\title{
Transonic Semispan Aerodynamic Testing of the Hybrid Wing Body with Over Wing Nacelles in the National Transonic Facility
}

\author{
David T. Chan* \\ NASA Langley Research Center, Hampton, VA, 23681 \\ John R. Hooker ${ }^{\dagger}$, Andrew Wick ${ }^{\ddagger}$ \\ Lockheed Martin Aeronautics Company, Marietta, GA, 30063 \\ Ryan W. Plumley ${ }^{\S}$, Cale H. Zeuneף, Michael V. Oll \\ Air Force Research Laboratory, Wright-Patterson AFB, OH, 45433 \\ Joshua A. DeMoss**, \\ Jacobs Technology, Inc., Hampton, VA, 23681
}

\begin{abstract}
A wind tunnel investigation of a 0.04-scale model of the Lockheed Martin Hybrid Wing Body (HWB) with Over Wing Nacelles (OWN) air mobility transport configuration was conducted in the National Transonic Facility at the NASA Langley Research Center under a collaborative partnership between NASA, the Air Force Research Laboratory, and Lockheed Martin Aeronautics Company. The wind tunnel test sought to validate the transonic aerodynamic performance of the HWB and to validate the efficiency benefits of the OWN installation as compared to the traditional under-wing installation. The semispan HWB model was tested in a clean wing configuration and also tested with two different nacelles representative of a modern turbofan engine and a future advanced high bypass ratio engine. The nacelles were installed in three different locations with two over-wing positions and one under-wing position. Five-component force and moment data, surface static pressure data, and aeroelastic deformation data were acquired. For the cruise configuration, the model was tested in an angle-of-attack range between -2 and 10 degrees at free-stream Mach numbers from 0.3 to 0.9 and at unit Reynolds numbers between 8 and 39 million per foot, achieving a maximum of $80 \%$ of flight Reynolds numbers across the Mach number range. The test results validated pretest computational fluid dynamic (CFD) simulations of the HWB performance including the OWN benefit and the results also exhibited excellent transonic drag data repeatability to within \pm 1 drag count. This paper details the experimental setup and model overview, presents some sample data results, and describes the facility improvements that led to the success of the test.
\end{abstract}

\footnotetext{
*Research Aerospace Engineer. Configuration Aerodynamics Branch. Member AIAA. david.t.chan@nasa.gov

†Senior Aeronautical Engineer. Lockheed Martin Aeronautics Company. Associate Fellow AIAA.john.r.hooker@lmco.com

$¥$ Aeronautical Engineer. Lockheed Martin Aeronautics Company. Member AIAA. andrew.wick@lmco.com

$\S$ Aerospace Engineer. Aerospace Systems Directorate RQVA. Member AIAA.ryan.plumley@us.af.mil

`Aerospace Engineer. Aerospace Systems Directorate RQVA. Member AIAA. cale.zeune@us.af.mil

॥ Aerospace Engineer. Aerospace Systems Directorate RQVA. Member AIAA. michael.ol@us.af.mil

**Test Engineer. National Transonic Facility. Member AIAA. joshua.a.demoss@nasa.gov
} 


\section{Nomenclature}

\begin{tabular}{|c|c|c|c|}
\hline \multicolumn{2}{|l|}{ Symbols } & AFRL & Air Force Research Laboratory \\
\hline$A F$ & Axial Force, lbf & AIP & Aerodynamic Interface Plane \\
\hline$C_{D}$ & Drag coefficient & ANOR & Analysis of Normalized Ranges \\
\hline$C_{L}$ & Lift coefficient & $\mathrm{AOA}$ & Angle-of-Attack \\
\hline$C_{m}$ & Pitching moment coefficient & BCRS & Balance Cavity Recirculation System \\
\hline$d_{2}$ & SPC quantity & $\mathrm{BL}$ & Boundary Layer \\
\hline$L / D$ & Lift over Drag & $\mathrm{BPR}$ & Bypass Ratio \\
\hline$M * L / D$ & Mach * Lift / Drag & CCD & Charge Coupled Device \\
\hline$M_{\infty}$ & Free-stream Mach number & CDISC & Constrained Direct Iterative Surface \\
\hline$N F$ & Normal Force, lbf & & Curvature \\
\hline$P M$ & Pitching Moment, in-lbf & CFD & Computational Fluid Dynamics \\
\hline$q_{\infty}$ & Free-stream dynamic pressure, psf & ESP & Electronically Scanned Pressure \\
\hline$R$ & Range (maximum - minimum) & $\mathrm{EU}$ & Engineering Units \\
\hline$r / D$ & Nacelle AIP radius over diameter & $\mathrm{F} \& \mathrm{M}$ & Force \& Moment \\
\hline$R / d_{2}$ & Individual dispersion quantity & FAST-MAC & Fundamental Aerodynamic Subsonic \\
\hline$R e$ & Reynolds number & & Transonic Modular Active Control \\
\hline$R M$ & Rolling Moment, in-lbf & FMS & Force Measurement System \\
\hline$T$ & Local temperature, deg $\mathrm{F}$ & FS & Full-scale \\
\hline$T_{t}$ & Total temperature, deg F & HWB & Hybrid Wing Body \\
\hline$U$ & Freestream velocity, $\mathrm{ft} / \mathrm{sec}$ & $\mathrm{IB}$ & Inboard \\
\hline$u$ & Local velocity, $\mathrm{ft} / \mathrm{sec}$ & LaRC & Langley Research Center \\
\hline$Y M$ & Yawing Moment, in-lbf & LED & Light Emitting Diode \\
\hline$\alpha$ & Angle-of-Attack, deg & $\mathrm{LMCO}$ & Lockheed Martin Aeronautics \\
\hline$\Delta T$ & Temperature gradient, $\operatorname{deg} \mathrm{F}$ & & Company \\
\hline$\delta$ & Boundary layer thickness, in & NASA & National Aeronautics and Space \\
\hline$\delta^{*}$ & Displacement thickness, in & & Administration \\
\hline$\hat{\sigma}$ & Estimated standard deviation & NTF & National Transonic Facility \\
\hline & & OB & Outboard \\
\hline Units & & OWN & Over Wing Nacelles \\
\hline${ }^{\circ}, \operatorname{deg}$ & degrees & RANS & Reynolds Averaged Navier-Stokes \\
\hline $\begin{array}{l}{ }^{\circ} \mathrm{F}, \operatorname{deg} \mathrm{F} \\
\mathrm{cts}\end{array}$ & $\begin{array}{l}\text { degrees Fahrenheit } \\
\text { counts }\end{array}$ & RCEE & $\begin{array}{l}\text { Revolutionary Configurations for } \\
\text { Energy Efficiency }\end{array}$ \\
\hline $\mathrm{ft}$ & feet & RTD & Resistance Temperature Detectors \\
\hline $\mathrm{ft} / \mathrm{sec}$ & feet per second & SMSS & Sidewall Model Support System \\
\hline in & inches & $\mathrm{SPC}$ & Statistical Process Control \\
\hline in-lbf & inch-pounds & T.S. & Tunnel Station \\
\hline lbf & pounds force & TRL & Technology Readiness Level \\
\hline $\mathrm{M} / \mathrm{ft}$ & millions/foot & TWICS & Transonic Wall Interference \\
\hline $\mathrm{nm}$ & nanometers & & Correction System \\
\hline psf & pounds per square foot & USM3D & Unstructured tetrahedral \\
\hline psi & pounds per square inch & & cell-centered RANS flow solver \\
\hline psid & pounds per square inch differential & UV & Ultra Violet \\
\hline Acronyms & & VMD & Video Model Deformation \\
\hline AATT & Advanced Air Transport Technology & $\mathrm{WT}$ & Wind Tunnel \\
\hline
\end{tabular}

\section{Introduction}

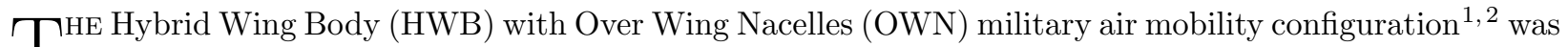
1 designed by the Lockheed Martin Aeronautics Company (LMCO) for the Air Force Research Laboratory (AFRL) sponsored Revolutionary Configurations for Energy Efficiency (RCEE) program. ${ }^{3,4}$ The program investigated aircraft configurations and technologies for a next generation U.S. Air Force air fleet supporting tactical mobility, strategic mobility, and tanking missions that would utilize significantly less fuel than the 
current fleet. The unconventional HWB with OWN configuration combines an efficient aerodynamic design with efficient integration of advanced engines and is designed to use $70 \%$ less fuel than the current fleet of military airlifters. Some of the distinguishing features of the HWB with OWN configuration are shown in Figure 1. The blending of the lifting forebody and the high aspect ratio outer wing combined with the efficient integration of the over-wing engine nacelles provide the configuration with its aerodynamic efficiency. The OWN engine location allows for larger high bypass ratio (BPR) engines and also provides a powered lift benefit at takeoff conditions. Finally, the conventional aft fuselage and T-tail empennage allow for robust stability \& control and handling qualities. It also retains the ability to perform standard aft loading through a cargo ramp and the ability to perform current military air mobility mission tasks such as airdrop.

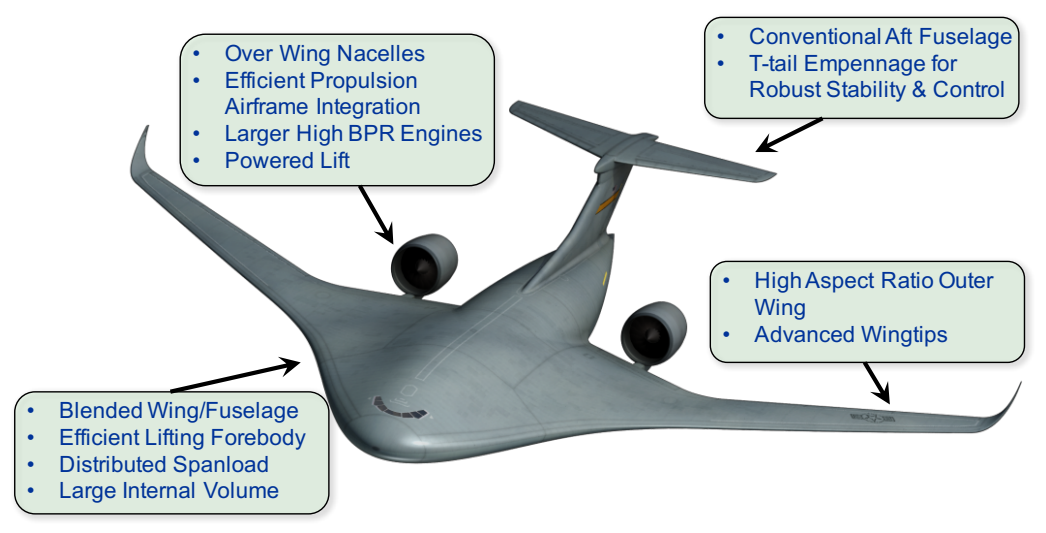

Figure 1. Features of the Lockheed Martin Hybrid Wing Body with Over Wing Nacelles air mobility configuration.

The impressive cruise performance predictions of the configuration were accomplished through an extensive aerodynamic shape optimization and engine integration effort by LMCO using computational fluid dynamic (CFD) simulations to reduce the overall drag and increase the aerodynamic efficiency of the configuration. However, the performance predictions needed to be validated through high-fidelity wind tunnel testing at flight or near-flight Reynolds numbers. The wind tunnel test would be a key step in the maturation of the configuration and its technologies and would help to raise the technology readiness level (TRL) of the configuration.

During this time period, it was recognized that AFRL and the National Aeronautics and Space Administration (NASA) Advanced Air Transport Technology (AATT) Project were engaged in common research programs exploring unconventional or transformational configurations to realize the goal of future ultra-energy-efficient subsonic transports for their respective military and civil ${ }^{5}$ uses. While the HWB was initially designed as a military airlifter, it could certainly be redesigned and repurposed for civil use such as a commercial freighter or commercial passenger aircraft. Therefore, AFRL and NASA entered into an interagency agreement in 2014 to jointly study the HWB with OWN configuration and help mature the configuration and its technologies. As part of the agreement, LMCO was under contract with AFRL to provide the wind tunnel model of the HWB and its engineering expertise, while NASA would provide testing time in its high Reynolds number facility. The three organizations have partnered in various capacities in past research and vehicle programs and have enjoyed successful collaboration in aligning their tools and test facilities to advance research capabilities. For example, NASA Langley computational tools such as CDISC ${ }^{6}$ and the USM3D ${ }^{7-9}$ flow solver are embedded in LMCO's design process and both AFRL and LMCO have used NASA wind tunnel test facilities.

Thus, a wind tunnel investigation of a 0.04-scale semispan model of the HWB with OWN configuration was conducted in the National Transonic Facility (NTF) at the NASA Langley Research Center to validate the transonic aerodynamic performance of the HWB, validate the efficiency benefits of the OWN installation as compared to the traditional under-wing installation, and validate the performance of the conventional highlift system. The capability of the NTF allowed for testing of the HWB model in the cruise configuration at Mach numbers between 0.3 and 0.9 at unit Reynolds numbers between 8 and 39 million per foot, achieving a maximum of $80 \%$ of flight Reynolds numbers across the Mach number range. In this configuration, the model was tested in an angle-of-attack range between -2 and 10 degrees. The test results validated the pretest CFD-simulated predictions of the HWB cruise performance and the results also exhibited excellent transonic drag data repeatability to within $\pm 1 \mathrm{drag}$ count. The model was also tested in the high-lift configuration at Mach numbers between 0.1 and 0.3 and an angle-of-attack range between -5 and 25 degrees.

This paper will present an overview of the wind tunnel test and the HWB model, as well as improvements and upgrades at the NTF that led to a successful test entry. Sample results from the test will be presented that will be mostly focused on facility-related data, such as balance thermal stability and data repeatability 
and its impact on the aerodynamic data and performance validation for the HWB. Measurements of NTF sidewall boundary layer heights will also be presented. The HWB aerodynamic performance validation results are mainly presented in a companion paper from LMCO (Ref. 10), but a few results are shown in this paper such as the effect of the standoff labyrinth seal on drag measurements, wing aeroelastic deflection and twist measurements, and a comparison of nacelle inlet total pressure recovery data between over-wing and under-wing nacelle installations.

\section{Wind Tunnel Description}

The $\mathrm{NTF}^{11,12}$ is one of a limited number of wind tunnel facilities that can achieve flight Reynolds numbers and Mach numbers for subsonic transport type aircraft for both cruise and high-lift operations. ${ }^{13}$ The tunnel is a fan-driven, closed-circuit, continuous-flow, pressurized wind tunnel capable of operating either in dry air at warm temperatures up to $120^{\circ} \mathrm{F}$ or in nitrogen gas from warm to cryogenic temperatures down to $-270^{\circ} \mathrm{F}$. The wind tunnel is capable of an absolute pressure range from 1 to 9 atmospheres, a Mach number range from 0.1 to 1.2 , and a maximum Reynolds number of $146 \times 10^{6}$ per foot. Figure 2 shows

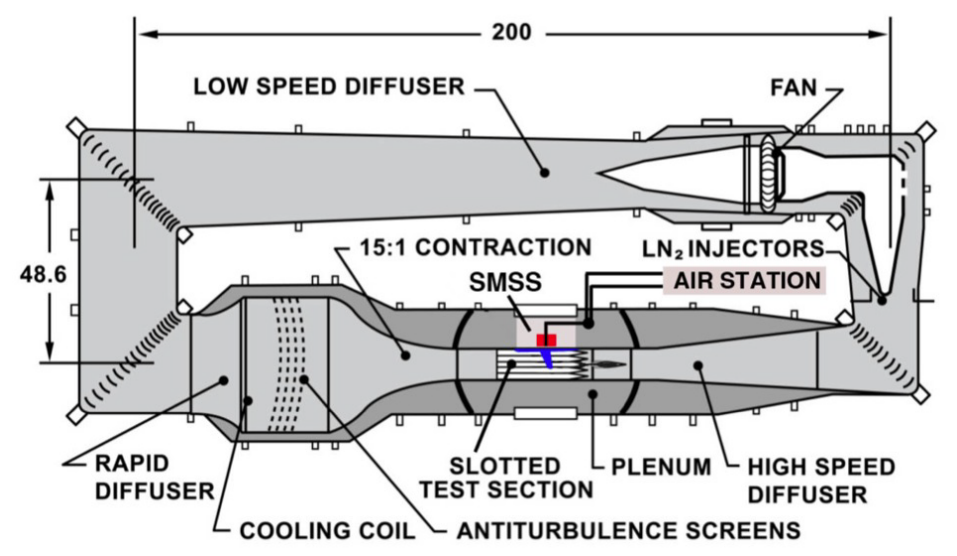

Figure 2. Major components of the NTF tunnel circuit including the SMSS and Air Station (linear dimensions in feet). the major components of the NTF tunnel circuit, including the location of the sidewall model support system (SMSS) used for semispan model testing. The NTF test section is 8.2 feet by 8.2 feet in cross section and 25 feet in length. The test section floor and ceiling are slotted (6 percent open), and the sidewalls are solid.

\section{A. Transonic Semispan Testing}

Semispan or halfspan model testing in the NTF was not in the original tunnel design. The capability $^{14-16}$ was added in the 1990s and used for product development of low-speed, high-lift configurations and then in 2007, the capability for semispan transonic cruise testing was initiated through a series of flow control and propulsion simulation tests. Typically, semispan models are used to acquire incremental aerodynamic data between model configurations, because with only one half of the configuration and the tunnel sidewall effects, it is not possible to obtain absolute aerodynamic data without some large data corrections. Because of the larger scale and size of a semispan model, higher Reynolds numbers are easier to achieve and more instrumentation such as pressure orifices can be placed in the model so semispan models are also commonly used for aerodynamic loads testing. Cruise performance testing is typically performed using a fullspan model, but a semispan model can be used if the data quality and data repeatability levels are sufficient. Correcting semispan aerodynamic data to absolute performance levels is also possible, but usually requires extensive CFD analysis of the model and tunnel to remove the tunnel sidewall effects from the data.

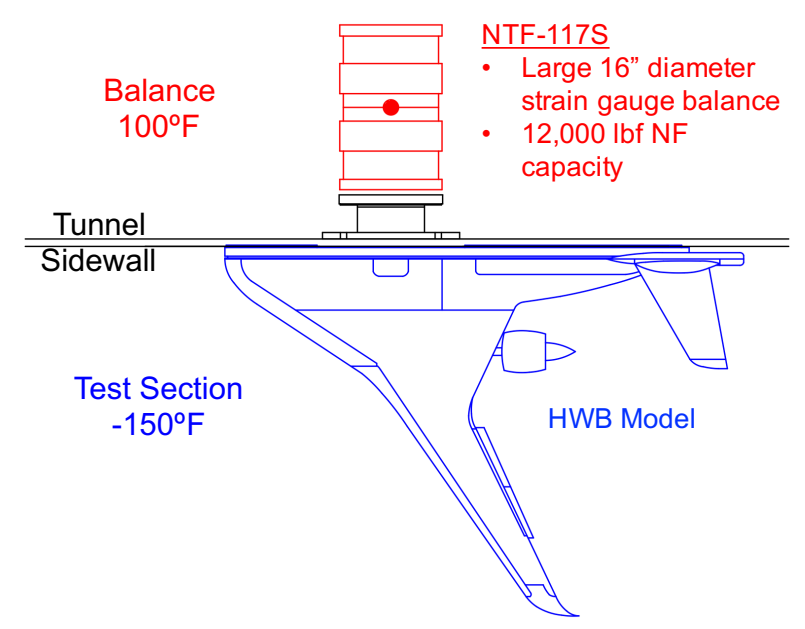

Figure 3. Simplified representation of the HWB semispan model installed to the NTF external force measurement system. Note the temperature difference between the test section and balance. 
In the NTF, semispan models are installed on the tunnel sidewall and are attached to the external Force Measurement System (FMS) inside the SMSS, which houses the large NTF-117S force and moment (F\&M) strain gauge balance. A nonmetric standoff is used to offset the model from the tunnel sidewall and the metric break is preserved through the use of a labyrinth seal. The challenge in this type of testing is that the balance is designed to operate at $100^{\circ} \mathrm{F}$ while the tunnel can operate at cryogenic temperatures such as $-150^{\circ} \mathrm{F}$, as shown in Figure 3. Large pressure gradients established by the aerodynamics of the test article can cause both cold air from the tunnel test section to be ingested into the balance cavity and heated air to be pulled out from the SMSS into the test section, through the gap in the model labyrinth seal. For data quality, the balance temperatures must remain stable with minimal temperature gradients across the balance. The SMSS provides a heated enclosure that maintains a stable temperature for the balance and the pitch mechanisms through the use of convective heat transfer provided by the closed loop Balance Cavity Recirculation System (BCRS). As shown in Figure 4, the BCRS constantly circulates heated air throughout the balance cavity and around the balance to counteract the cold air flow ingestion from the tunnel test section.

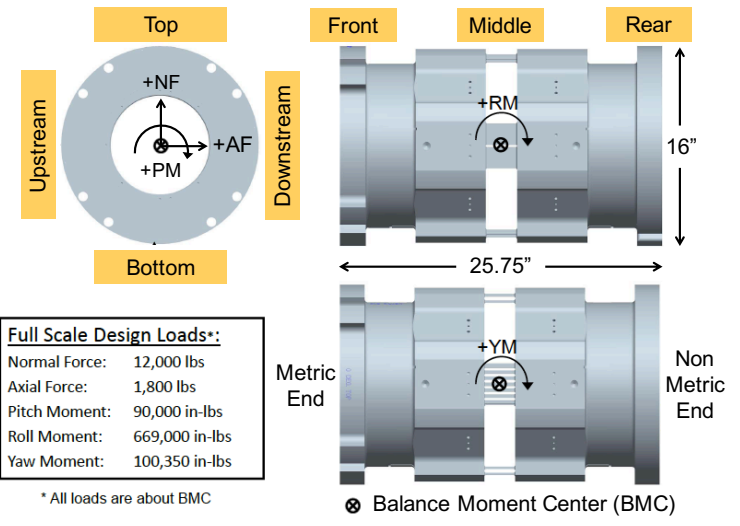

(a) NTF-117S Balance

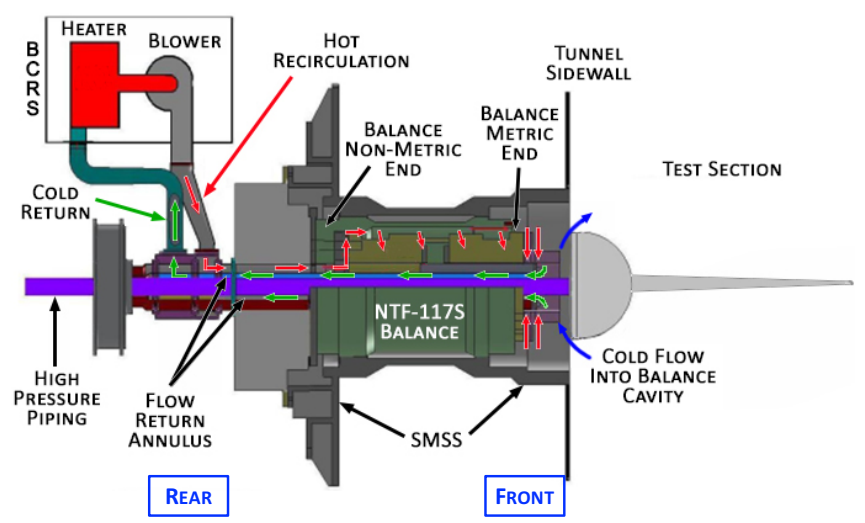

(b) Balance Cavity Recirculation System

Figure 4. NTF-117S strain gauge balance and Balance Cavity Recirculation System used for semispan testing at the NTF.

\section{B. Data Quality Improvements}

Several flow control and propulsion simulation experiments were the first uses of the transonic semispan test capability at NTF. The test entries of the Fundamental Aerodynamic Subsonic Transonic Modular Active Control (FAST-MAC) model $^{17-20}$ and the Lockheed Martin Speed Agile model $^{21,22}$ exposed shortcomings in the transonic semispan capability at NTF, specifically in data quality and data repeatability. The levels of data repeatability from those tests were unacceptable for assessing cruise performance of the configurations and made it difficult to trust some of the test results. Those tests were also complicated by the delivery of high pressure air that bridged the nonmetric and metric portions of the F\&M balance. The major sources of the problem were determined to be a nonrepeatable load path in the SMSS FMS and thermal instability of the F\&M balance during cryogenic tunnel operations.

Upgrades and improvements to the SMSS

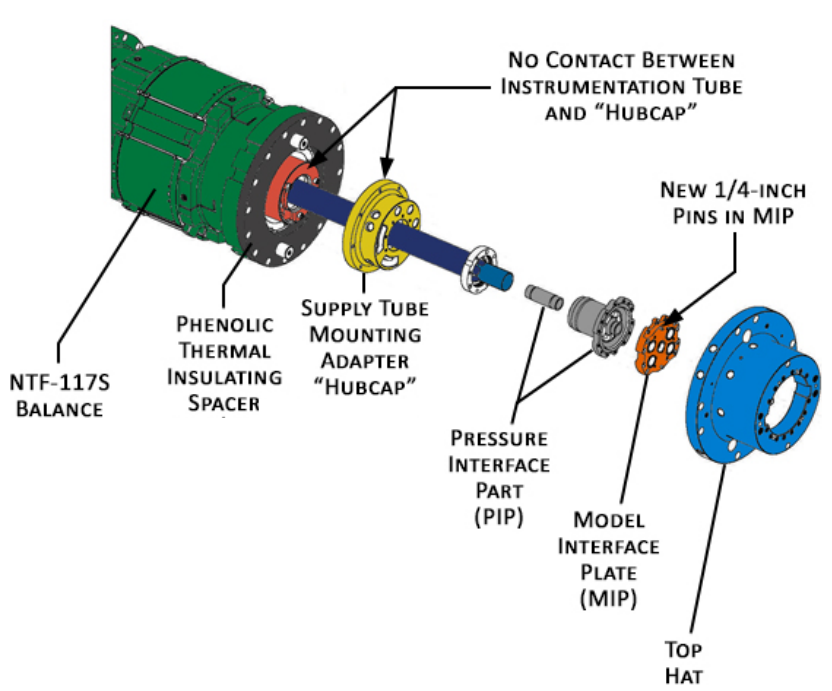

Figure 5. SMSS Force Measurement System arrangement and assembly.

FMS were completed in recent years to fix these problems resulting in positive effects on data quality 
and data repeatability. ${ }^{23,24}$ The load path was improved with the addition of a mounting adapter that was installed to the front of the balance and kept the air delivery pipes secured in place and eliminated the instrumentation tube from affecting the load path. Furthermore, two pins were added to the model interface plate to ensure a repeatable installation. These improvements are shown in Figure 5 and have contributed to very repeatable wind-off zero loads during semispan tests.

The thermal stability of the F\&M balance was improved through a series of upgrades to the BCRS. The existing instrumentation tube was replaced with a larger diameter carbon-fiber tube, which increased the annular area for the BCRS flow path and thereby increased the allowable flow rate. Additionally, the BCRS blower motor and heater wiring were upgraded to allow the BCRS to provide more heat at higher flow rates. Finally, the BCRS control system was improved to provide better and quicker adjustments to changing tunnel operating conditions and prevent temperature gradients from forming across the balance. Other minor improvements such as sealing small gaps and holes in the back of the SMSS and in the model have also contributed to better temperature stability.

Other modifications ${ }^{25,26}$ at the NTF have focused on improving overall data quality and data repeatability. Several data processing techniques explored during these studies were determined to significantly improve data repeatability and are now part of the standard data reduction process at the facility. Acquiring longer duration data points to increase the number of samples in a data point decreased the scatter seen in the averaged data values. These longer data points also allow the use of conditional data sampling, where only samples that are within a specified Mach number tolerance are used in the averaged data values. The conditional sampling technique requires that the data samples are time-aligned properly so that instrumentation time lags are taken into account, and that there are enough data samples within tolerance to create a proper averaged data value. The technique has been shown to significantly improve transonic drag data repeatability $\left(M_{\infty} \geq 0.8\right)$ due to the high correlation between Mach number and aerodynamic drag at those Mach numbers.

A third test entry (denoted FAST-MAC 2.5) of the FAST-MAC model was conducted before the HWB test to evaluate the improvements described above and to ensure that the drag repeatability levels were within the desired levels of the HWB test team. The model was tested only in the cruise configuration, mainly at Mach numbers of 0.85 and 0.88 at both warm and cryogenic temperatures. The first phase of the test included flow control simulation with high pressure air, while in the second phase of the test, the flow control hardware and all air supply pipes were removed from the SMSS. In both phases of the test, the drag data repeatability levels were significantly improved compared to previous FAST-MAC test entries and were very close to meeting the desired goals $( \pm 2.5 \mathrm{lbf})$ of the HWB test team. This provided confidence that with just a few more small improvements and adjustments based on lessons learned, the HWB test would exhibit drag repeatability levels that were as good or better than what was achieved in the FAST-MAC 2.5 test entry. In Figure 6, the progression of improvement with time of the semispan transonic drag repeatability for the FAST-MAC model is shown, and the improvement continued with the HWB test, which exhibited axial force repeatability of $\pm 0.5 \mathrm{lbf}$ corresponding to \pm 1 drag count repeatability.

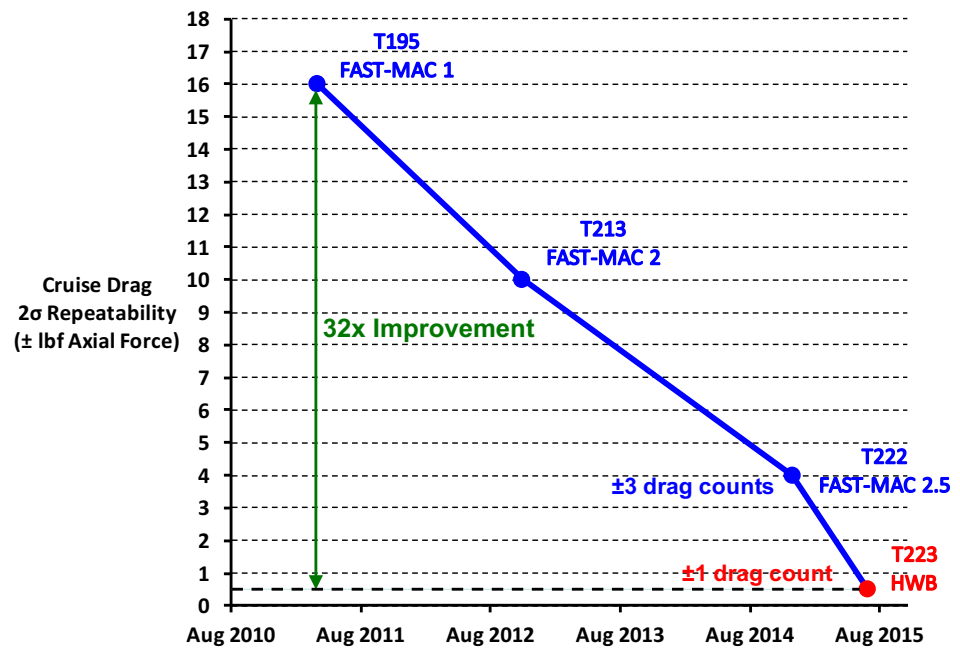

Figure 6. Semispan Transonic Cruise Drag Repeatability Improvements at NTF in recent years. 


\section{Experimental Setup}

\section{A. Test Objectives and Requirements}

The main objectives of the wind tunnel test were to validate the transonic aerodynamic performance of the HWB, validate the efficiency benefits of the OWN installation as compared to the traditional under-wing installation, and validate the performance of the conventional high-lift system. To achieve these objectives, there were several main requirements that a wind tunnel facility needed to meet. These included the ability to run at both subsonic and transonic Mach numbers, the ability to test at flight or near-flight Reynolds number for the HWB, and the ability to measure aerodynamic drag to within a \pm 2.5 lbs accuracy in order to distinguish between configuration differences. While there are many wind tunnels that can run at sub-

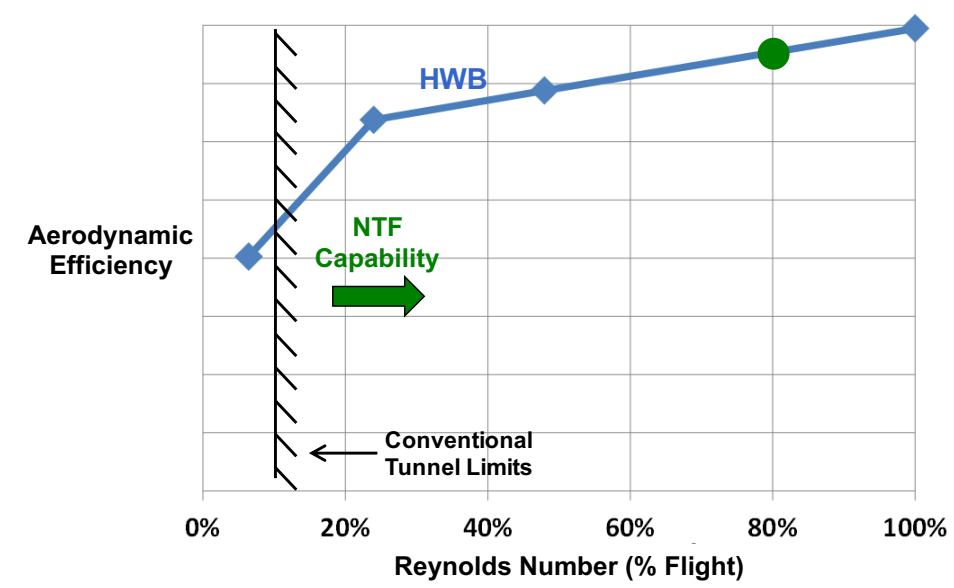

Figure 7. Reynolds number requirement for wind tunnel testing of the HWB based on pretest CFD predictions of aerodynamic efficiency as a function of $R e$. sonic and transonic Mach numbers, there are only a limited number of facilities that can run at high Reynolds numbers. The HWB Reynolds number requirements led to testing at the NTF since conventional wind tunnels could not achieve the Reynolds number requirements as shown in Figure 7. The pretest CFD predictions of aerodynamic efficiency as a function of Reynolds number showed that the trend with Reynolds number was linear above $25 \%$-flight $R e$. Therefore, the desire was to be able to acquire data at Reynolds numbers that were in that linear region to verify the predictions. The NTF was capable of achieving $100 \%$-flight $R e$ conditions for the HWB, but due to risk of inadequate BCRS performance, the test was limited to 80\%-flight Re. Finally, the drag accuracy requirement was achieved through the improvements made to transonic semispan testing at the NTF as presented earlier.

\section{B. Test Article}

The test article was a 0.04-scale semispan model of the LMCOdesigned HWB with OWN air mobility configuration. An overview of the model is shown in Figure 8. The model was fabricated primarily out of 13-8 H1150M stainless steel to withstand the cryogenic temperatures and large aerodynamic loads generated at high dynamic pressure test conditions in the NTF. The model was equipped with two different flow-through nacelles representative of a modern turbofan engine (General Electric GEnX) and a future advanced high bypass ratio engine (Rolls Royce Ultra Fan). The nacelles could be installed in three different locations (two over-

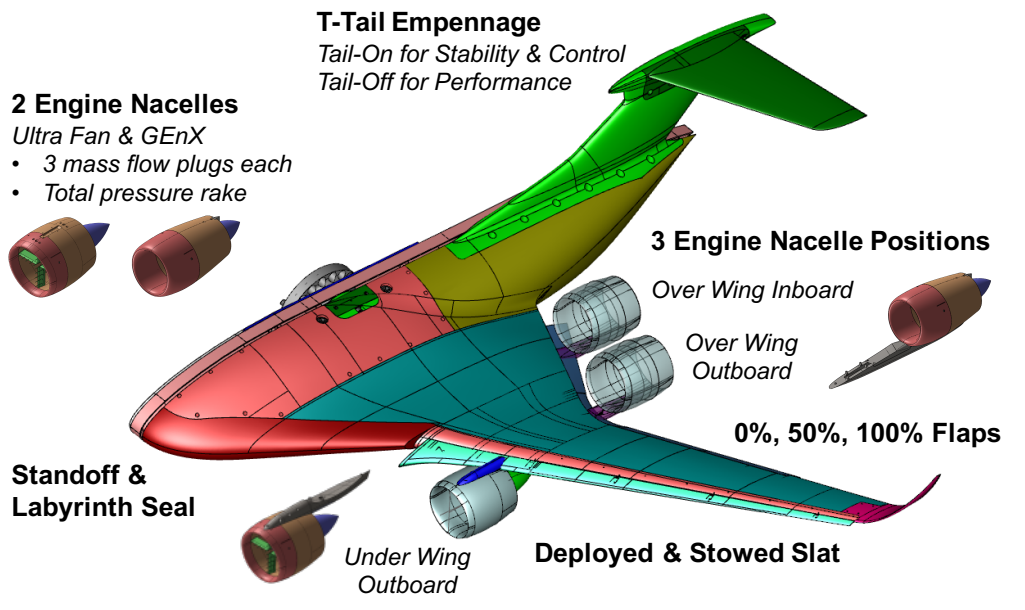

Figure 8. Overview of the $4 \%$-scale HWB with OWN model tested in the NTF. wing locations and one under-wing location) and each nacelle possessed three different sized mass flow plugs 
to regulate the mass flow through each nacelle. The over-wing inboard location was at approximately $26 \%$ semispan and both the over-wing outboard and under-wing outboard locations were the same at approximately $42 \%$ semispan. The model could be configured in the cruise configuration, which was the focus of the experiment, but could also be configured in takeoff and landing high-lift configurations with the slat and flaps deployed. Finally, a T-tail empennage could be installed to evaluate stability and control characteristics. Photographs of the model in the cruise and high-lift configurations as installed in the NTF test section are shown in Figure 9.
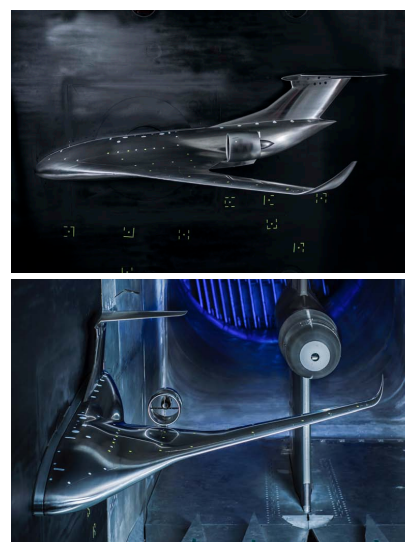

(a) Cruise configuration with Over Wing and Under Wing Nacelles
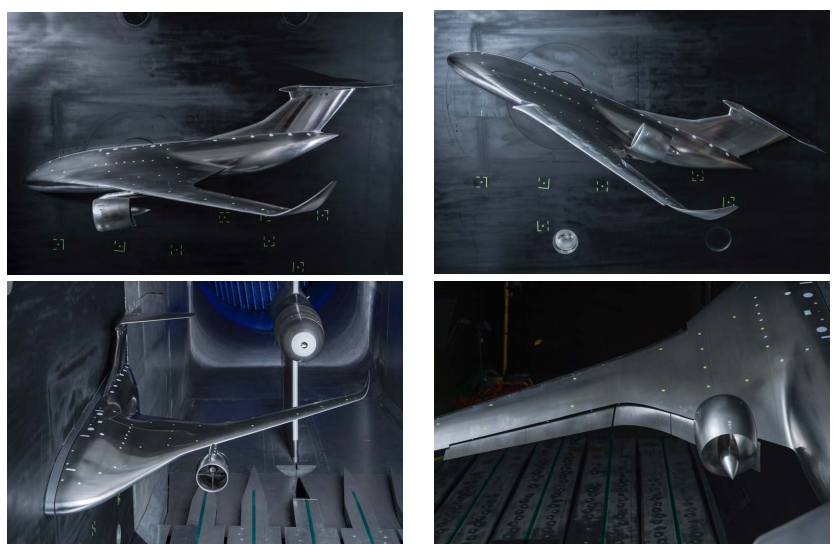

(b) High-Lift configuration with slat and flaps deployed

Figure 9. Photographs of the HWB model in the (a) cruise and (b) high-lift configurations.

The GEnX and Ultra Fan flow-through nacelles are shown in more detail in Figure 10. Each nacelle has a total pressure rake that is held and captured between the forward and aft parts of the nacelle for extra strength. Each nacelle also has a strut to hold the three different-sized mass flow plugs. It can be seen that the Ultra Fan nacelle has a larger diameter, shorter body length, and thinner inlet lip than the GEnX nacelle. The Ultra Fan nacelle has about a 50\% larger area at the aerodynamic interface plane (AIP) of the nacelle where the rakes are located. Furthermore, the Ultra Fan nacelle has a slightly larger inlet scarf angle than the GEnX nacelle and when the nacelles are installed in the over-wing position, they are rotated so that the inlet scarf angle is reversed, as shown in Figure 11.

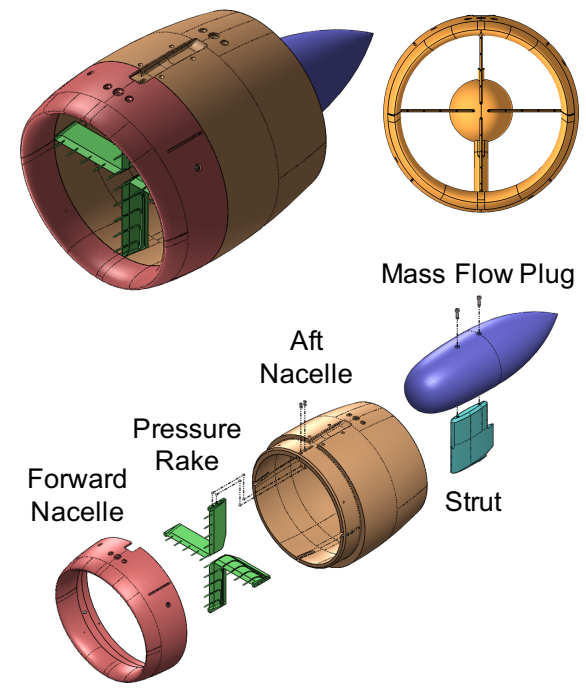

(a) Ultra Fan nacelle assembly
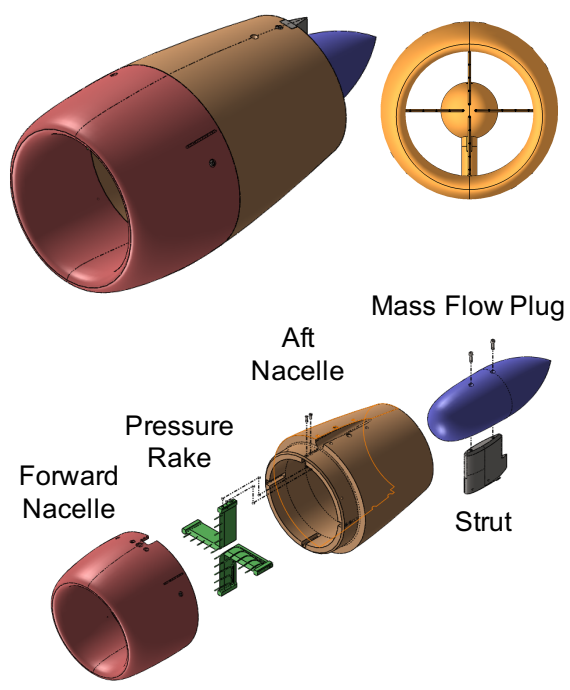

(b) GEnX nacelle assembly

Figure 10. Engine nacelle model assemblies for the (a) Ultra Fan and (b) GEnX engines. 
Ultra Fan
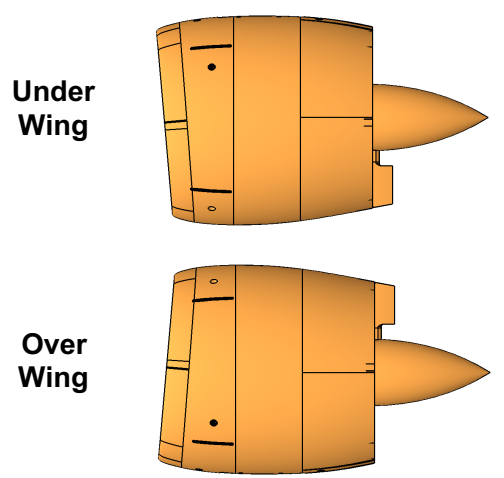

GEnX
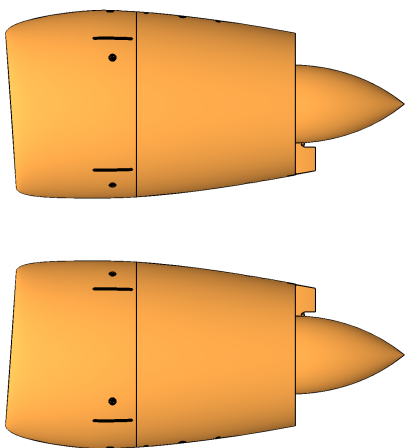

Figure 11. Comparison of nacelle inlet scarf angle between over-wing and under-wing installations.

The HWB model was the first instance of including a T-tail empennage on an NTF semispan model. The tail would be installed for only a subset of runs in order to assess pitch characteristics of the configuration. The design for the vertical stabilizer was challenging due to its close proximity to the tunnel sidewall. It needed to have enough strength to withstand the loads generated by the horizontal tail, but also needed to minimize interference with the tunnel sidewall. The vertical stabilizer went through several design iterations to minimize interference with the tunnel sidewall because CFD simulations showed that keeping the inboard half of the vertical stabilizer created a convergent/divergent nozzle effect with the sidewall and led to shockinduced flow separation at the trailing edge. ${ }^{10}$ The final design, as shown in Figure 12, included a flat surface on the inboard side to minimize the interference with the sidewall but retained the upper bullet shape in order to have enough material to mount the horizontal tail.

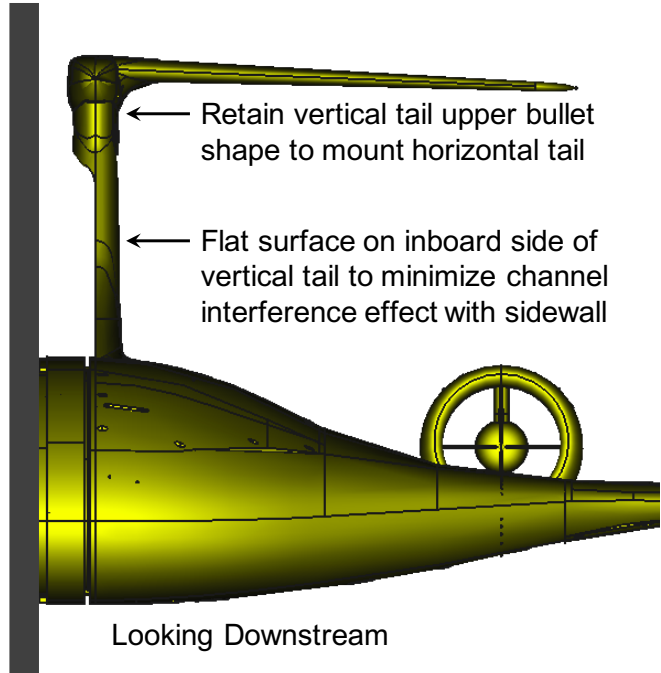

(a) Design of HWB vertical tail

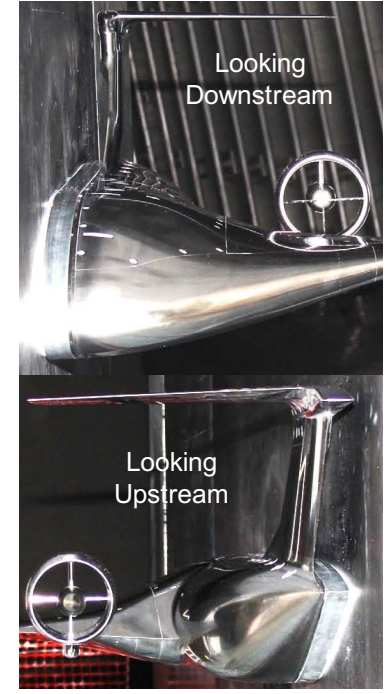

(b) Photos of HWB T-tail empennage in NTF test section

Figure 12. Semispan T-tail empennage design for the HWB model.

A nonmetric standoff is used to offset the model from the tunnel sidewall and the metric break is preserved through the use of a labyrinth seal. Large pressure gradients established by the aerodynamics of the test article can cause both cold air from the tunnel test section to be ingested into the balance cavity and heated air to be pulled out from the SMSS into the test section, through the gap in the model labyrinth seal. Therefore, the design of the labyrinth seal is intended to provide enough gap for the metric break so that the model will not foul under large aerodynamic loads, but the gap also needs to be small enough to prevent excessive air flow inside the model. An S-shaped labyrinth seal design was chosen for the HWB model, as 
shown in Figure 13, based on previous designs from other semispan models tested at the NTF. The figure also shows the assembly of the standoff and model labyrinth to the tunnel hardware. The standoff distance was chosen to be nominally 2 inches away from the sidewall based on guidelines developed for semispan high-lift tests at NTF through computational ${ }^{27,28}$ and experimental ${ }^{14,29}$ studies. While this standoff distance seems to also work fine for semispan transonic tests, it is understood that it may not be the optimal offset distance for transonic testing.

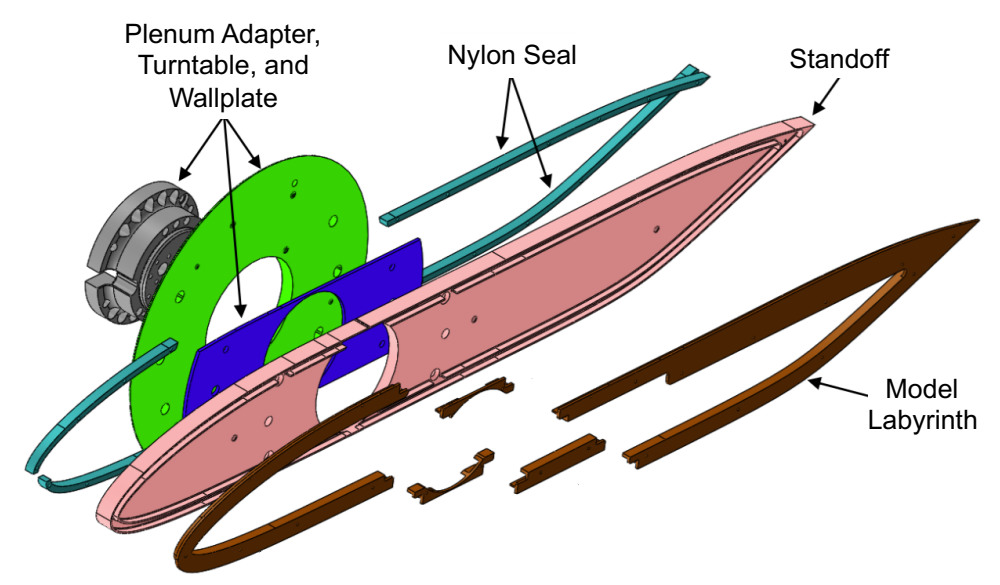

(a) Assembly of HWB model standoff and labyrinth

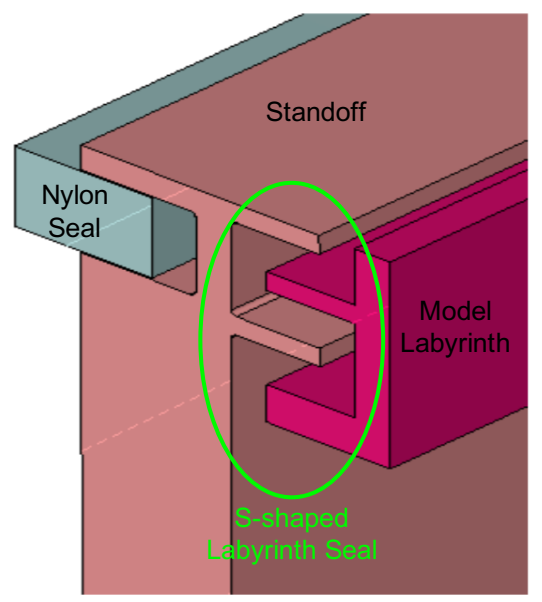

(b) Design of S-shaped labyrinth seal

Figure 13. Labyrinth seal design for the HWB model.

\section{Measurements and Instrumentation}

\section{Force and Moment Balance}

The NTF- $117 \mathrm{~S}^{30}$ balance shown earlier in Figure 4(a) is a large five-component (no side force measurement capability) strain gauge balance that is mounted inside the SMSS and is the primary FMS for semispan models in the NTF. The balance is 16 inches in diameter and about 26 inches in length and has RTD temperature sensors all around the balance to be able to monitor temperature gradients that may develop from the front-to-rear, top-to-bottom, and upstream-to-downstream directions. Table 1 shows the design loads of the balance and the results of the laboratory calibration. The calibration accuracies are presented both as a percentage of full-scale load and in engineering units of lbf or in-lbf. The right side of the table converts the numbers to aerodynamic coefficient accuracies at a few conditions for the HWB model.

Table 1. NTF-117S laboratory balance calibration.

\begin{tabular}{|c|c|c|c|c|c|c|}
\hline \multirow[b]{2}{*}{$\begin{array}{c}\text { Balance } \\
\text { Component }\end{array}$} & \multirow[b]{2}{*}{$\begin{array}{c}\text { Calibration } \\
\text { Load Range }\end{array}$} & \multicolumn{2}{|c|}{$\begin{array}{c}\text { Calibration } \\
\text { Accuracy }\end{array}$} & \multicolumn{3}{|c|}{$\begin{array}{c}\text { Coefficient Accuracy for } \\
\text { HWB Model }\end{array}$} \\
\hline & & $\%$-FS & EU & $\begin{array}{c}M_{\infty}=0.8 \\
R e=8 \mathrm{M} / \mathrm{ft}\end{array}$ & $\begin{array}{c}M_{\infty}=0.8 \\
R e=23 \mathrm{M} / \mathrm{ft}\end{array}$ & $\begin{array}{c}M_{\infty}=0.8 \\
R e=37 \mathrm{M} / \mathrm{ft}\end{array}$ \\
\hline $\mathrm{AF}$ & $\pm 1,800 \mathrm{lbf}$ & 0.14 & $\pm 2.52 \mathrm{lbf}$ & \pm 0.0005 & \pm 0.0003 & \pm 0.0002 \\
\hline NF & $\pm 12,000 \mathrm{lbf}$ & 0.05 & $\pm 6 \mathrm{lbf}$ & \pm 0.0011 & \pm 0.0006 & \pm 0.0006 \\
\hline $\mathrm{PM}$ & $\pm 90,000$ in-lbf & 0.16 & \pm 144 in-lbf & \pm 0.0024 & \pm 0.0013 & \pm 0.0012 \\
\hline $\mathrm{RM}$ & $\pm 669,000$ in-lbf & 0.12 & \pm 802.8 in-lbf & \pm 0.0027 & \pm 0.0015 & \pm 0.0013 \\
\hline YM & $\pm 110,350$ in-lbf & 0.09 & \pm 99.3 in-lbf & \pm 0.0003 & \pm 0.0002 & \pm 0.0002 \\
\hline
\end{tabular}




\section{Wing Surface Static Pressures}

The HWB model was designed with static pressure orifices on the upper and lower surfaces of the wing and also a few orifices on the upper surface of the main body. Figure 14 shows the location of the pressure orifices on the HWB model. The pressure orifice rows on the wing are located at semispan locations of $26 \%, 47 \%$, and $61 \%$ and these locations were chosen for specific reasons. The $26 \%$ semispan location was chosen to line up with the center of the engine nacelle when it is installed in the overwing inboard location and the upper surface pressure orifices cover from the leading edge to $85 \%$ of the chord length. There are also pressure orifices on the lower surface of the wing at this semispan location and they cover from the leading edge to $60 \%$ of the chord length. Part of the benefit of the

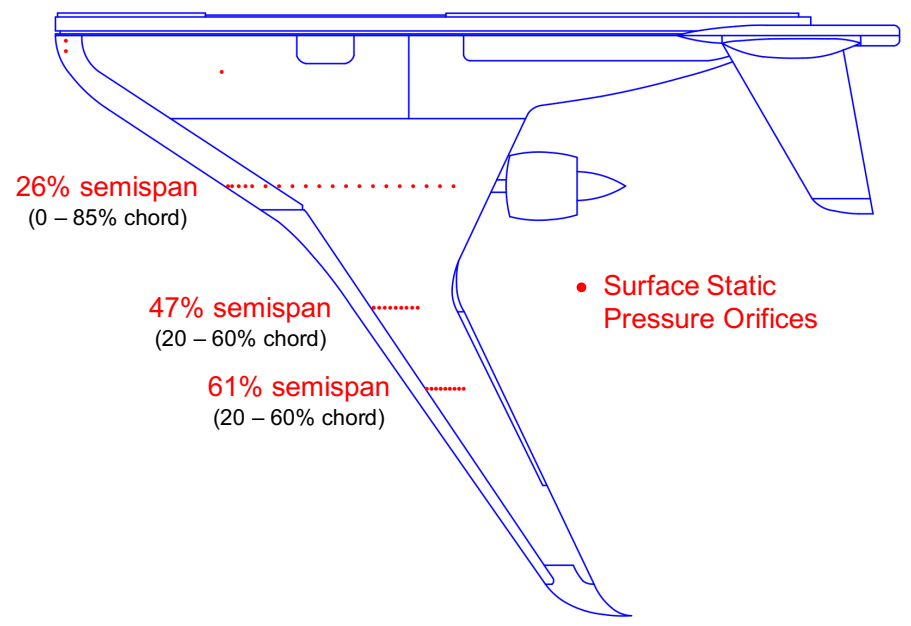

Figure 14. Surface static pressure orifices on the wing and fuselage of the HWB model.

over-wing inboard location is that it has a large body chord length ahead of the nacelle which acts as a flow straightener to keep the flow attached and the pressure orifices helped to verify that effect. The second row of pressure orifices at $47 \%$ semispan is located close to the wing trailing-edge break and is also close to the semispan location for the over-wing and under-wing outboard engine nacelle installations. Finally, the third row of pressure orifices at $61 \%$ semispan was at the farthest outboard location where there was still enough wing thickness to allow for pressure instrumentation. The second and third row of pressures only included orifices on the upper surface of the wing covering $20 \%$ to $60 \%$ of the chord length in order to capture the shock location on the wing.

\section{Nacelle Total Pressure Rake}

In addition to the static pressure orifices on the wing, each engine nacelle had a total pressure rake to acquire data on possible inlet distortion, especially for the over-wing nacelle installations. The rakes were located at the aerodynamic interface plane (AIP) in a cruciform arrangement to measure the radial pressure variations and consisted of five total pressure probes on each leg of the rake. There were also four static pressure orifices on the inside face of the nacelles at radial angles of $45^{\circ}$ multiples. These were used in conjunction with the total pressure measurements to calculate a mass flow through the nacelles. Figure 15 shows the layout of the total and static pressure measurements in the nacelle and also shows a photo of the Ultra Fan nacelle rake.

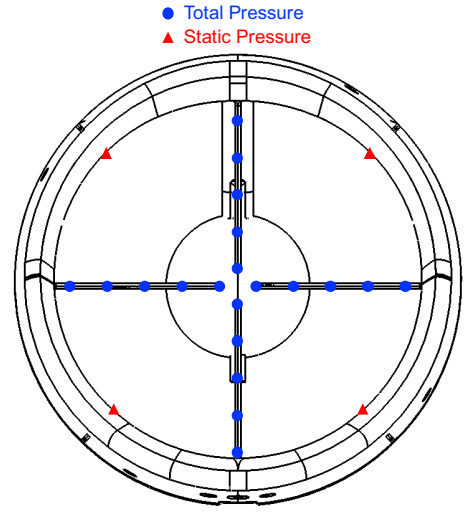

(a) Nacelle rake total and static pressure layout

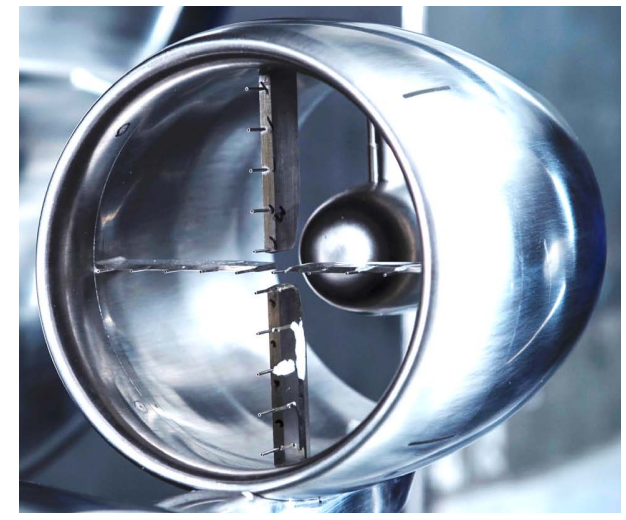

(b) Photo of Ultra Fan nacelle rake

Figure 15. Total pressure rake in engine nacelles on the HWB model. 


\section{ESP Packages and Heated Enclosure}

The wing pressures and nacelle rake pressures were measured using two 64-port 30-psid Electronically Scanned Pressure (ESP) packages housed inside a heated enclosure in the model, as shown in Figure 16. Element heaters inside the enclosure and the surrounding foam insulation are used to keep the ESP packages at an elevated temperature while the tunnel operates at cryogenic temperatures and transonic speeds.

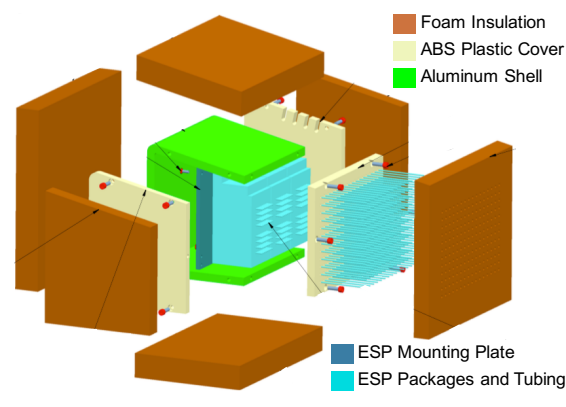

(a) Design of ESP heated enclosure

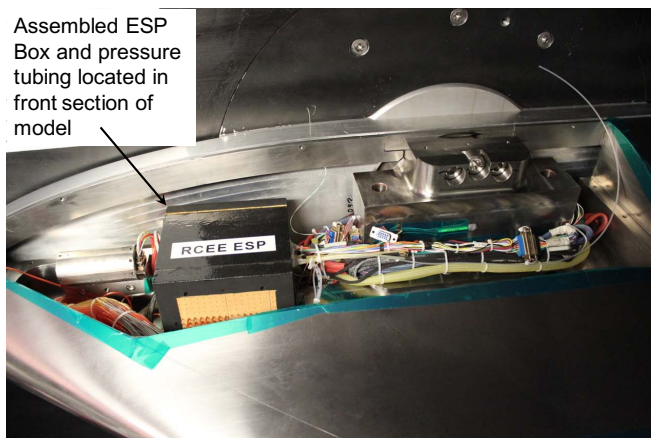

(b) Location of ESP box in HWB model

Figure 16. Heated enclosure for ESP packages in the HWB model.

\section{Angle-of-Attack Package}

Model angle-of-attack (AOA) was measured with the NTF 11-9 accelerometer package. This cylindrical package houses one Q-Flex servo accelerometer to measure model angle-of-attack and one electrolytic bubble for leveling. The package has its own heater controller to keep the temperature at $160^{\circ} \mathrm{F}$ while the tunnel is operating at cryogenic conditions. During this test, the 11-9 package was bolted to the AOA mounting plate near the nose of the HWB model with the connector facing backwards. A photo of the model accelerometer package is shown in Figure 17.

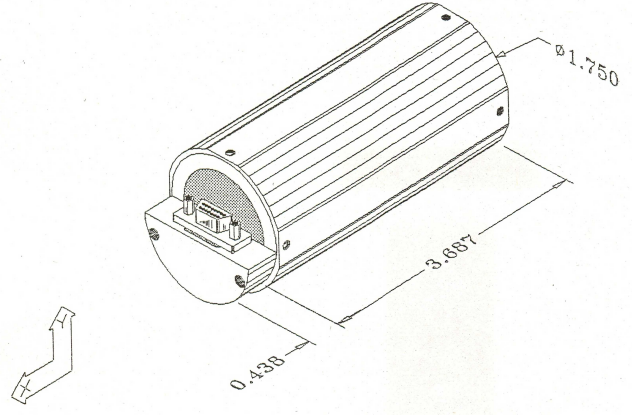

(a) Drawing of Package

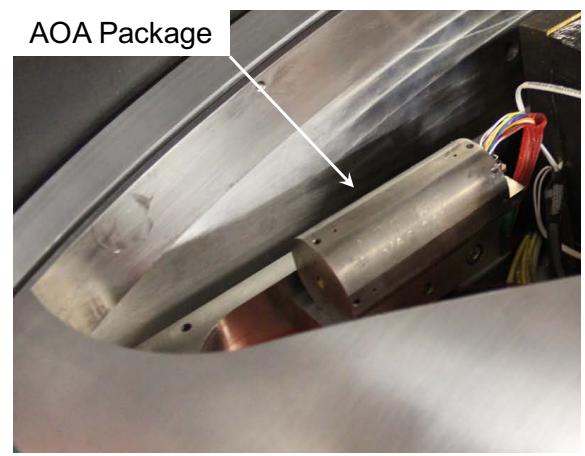

(b) Photo of AOA package in HWB model

Figure 17. AOA package in the HWB model.

\section{Test Conditions and Test Matrix}

The capability of the NTF allowed for testing of the HWB with OWN model at a wide range of Mach number and Reynolds number conditions. Also, since the HWB model could be assembled in both cruise and high-lift configurations, there were different angle-of-attack ranges for each configuration. A summary of the test conditions is shown in Table 2. Furthermore, the large Mach-Reynolds number operations envelope of the NTF allowed for testing of the HWB model at either constant Reynolds number or constant \%-of-flight Reynolds number conditions, as shown in Figure 18. A maximum of 80\%-of-flight Reynolds number was achieved at a tunnel temperature of $-150^{\circ} \mathrm{F}$. 
Table 2. Summary of test conditions.

\begin{tabular}{|c|c|c|c|c|}
\hline \multirow{2}{*}{$\begin{array}{c}\text { Model } \\
\text { Configuration }\end{array}$} & \multicolumn{4}{|c|}{ Test Conditions } \\
\cline { 2 - 5 } & $M_{\infty}$ & $R e, \mathrm{M} / \mathrm{ft}$ & $T_{t},{ }^{\circ} \mathrm{F}$ & $\alpha, \operatorname{deg}$ \\
\hline Cruise & 0.3 to 0.9 & 8 to 39 & -150 to 120 & -2 to 10 \\
\hline $\begin{array}{c}\text { High-Lift } \\
\text { (Take-off \& Landing) }\end{array}$ & 0.1 to 0.3 & 0.7 to 7.8 & 90 & -5 to 25 \\
\hline
\end{tabular}

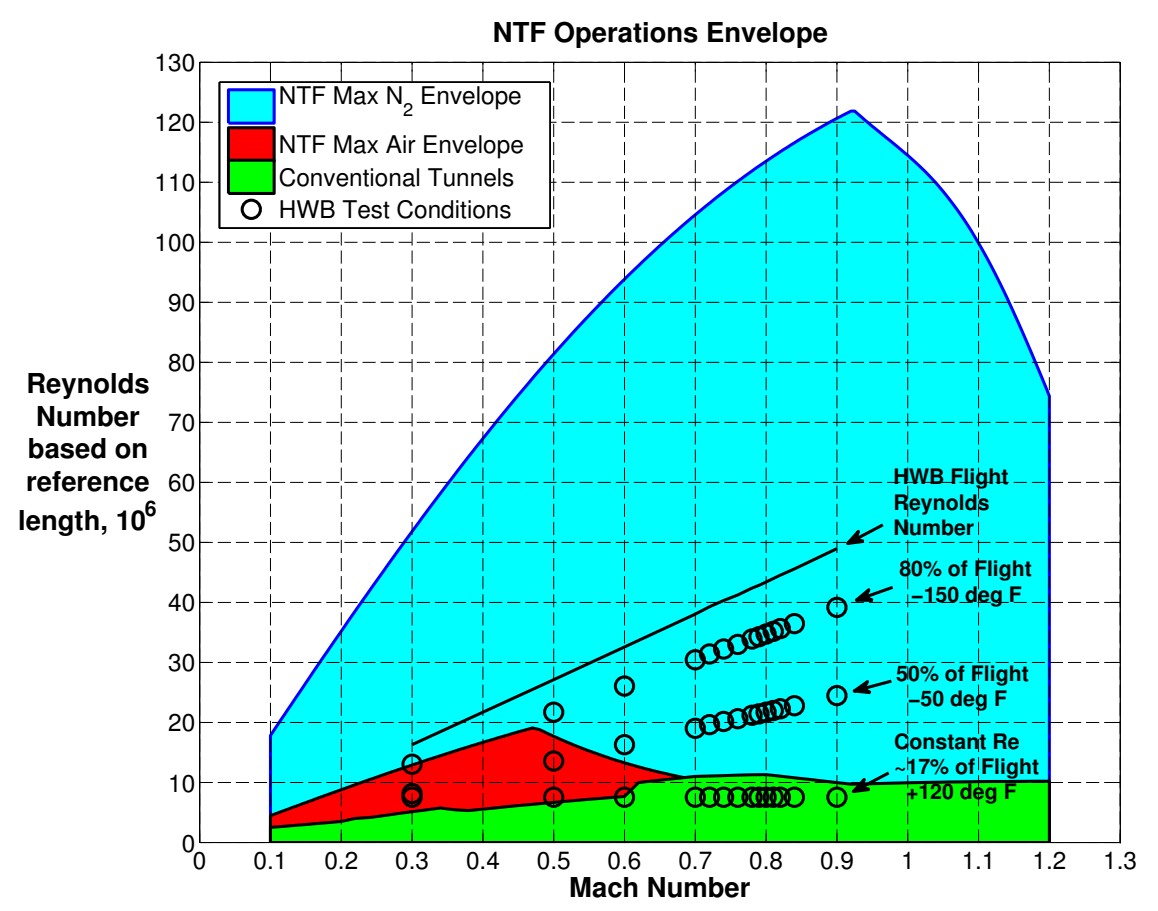

Figure 18. NTF Mach-Reynolds number operating envelope showing test conditions for HWB cruise configuration.

The test matrix shown in Table 3 was focused primarily on cruise performance testing with limited testing of the high-lift configurations. The matrix was originally sequenced to perform all required testing in air mode operations before crossing over to nitrogen mode operations at cryogenic temperatures. Additional funding allowed for further testing in air mode after the cryogenic portion of the matrix. For the cruise configuration in air mode, data were acquired at a constant unit Reynolds number of $8 \mathrm{M} / \mathrm{ft}$ for Mach numbers between 0.3 to 0.9 for the different combinations of engine nacelle type, engine nacelle location, mass flow plug sizes, and tail installation. The baseline clean wing cruise configuration consisted of the slat stowed and flaps at $0 \%$ with no engine or tail installed. For the high-lift configuration, the model was tested at Mach numbers between 0.1 and 0.3 with the slat deployed and the flaps deflected at either $50 \%$ or $100 \%$ corresponding to the takeoff and landing configurations, respectively. In nitrogen mode and cryogenic temperatures, data were acquired at a constant $50 \%$ and $80 \%$ of flight Reynolds numbers for Mach numbers between 0.6 and 0.84 for the baseline clean wing configuration. Data were also acquired at $80 \%$ of flight Reynolds number for the configurations with the Ultra Fan nacelle at the over-wing inboard and under-wing outboard positions. Similarly, data were also acquired at $50 \%$ of flight Reynolds number for the configurations with the GEnX nacelle at the over-wing inboard and under-wing outboard positions. Toward the end of the test, additional funding allowed for exploration of labyrinth seal effects and allowed for acquiring boundary layer height measurements. 
Table 3. Summary of test matrix for HWB test at NTF.

\begin{tabular}{|c|c|c|c|c|c|c|c|c|c|c|c|c|}
\hline Flight Phase & Flaps & Slat & Tail & Engine & Engine Position & Flow Plug & $\begin{array}{l}\text { Tunnel } \\
\text { Mode }\end{array}$ & $\begin{array}{c}\begin{array}{c}\text { Tunnel } \\
\text { Temperature } \\
\text { (deg F) }\end{array} \\
\end{array}$ & $\begin{array}{c}\text { Unit Reynolds } \\
\text { Number }\end{array}$ & Alpha (deg) & Mach Number & Comment \\
\hline Cruise & $0 \%$ & Stowed & - & - & - & - & Air & 120 & $8 \mathrm{M} / \mathrm{ft}$ & $\begin{array}{r}-2 \text { to } 10(M<0.7) \\
-2 \text { to } 6.5(M>=0.7)\end{array}$ & $0.3-0.9$ & \\
\hline Cruise & $0 \%$ & Stowed & - & GEn $X$ & Over Wing Inboard & Small, Medium, Large & Air & 120 & $8 \mathrm{M} / \mathrm{ft}$ & $\begin{aligned} &-2 \text { to } 10(M<0.7) \\
&-2 \text { to } 6.5(M>=0.7)\end{aligned}$ & $0.3-0.9$ & \\
\hline Cruise & $0 \%$ & Stowed & - & Ultra Fan & Over Wing Inboard & Small, Medium, Large & Air & 120 & $8 \mathrm{M} / \mathrm{ft}$ & $\begin{aligned} &-2 \text { to } 10(M<0.7) \\
&-2 \text { to } 6.5(M>=0.7)\end{aligned}$ & $0.3-0.9$ & \\
\hline Cruise & $0 \%$ & Stowed & On & Ultra Fan & Over Wing Inboard & Medium & Air & 120 & $8 \mathrm{M} / \mathrm{ft}$ & $\begin{aligned}-2 & \text { to } 10(M<0.7) \\
-2 \text { to } 6.5(M> & >0.7)\end{aligned}$ & $0.3-0.9$ & \\
\hline Landing & $100 \%$ & Deployed & On & -- & - & - & Air & 120 & $1-8 \mathrm{M} / \mathrm{ft}$ & -5 to 25 & $0.1-0.3$ & \\
\hline Take-off & $50 \%$ & Deployed & On & - & - & - & Air & 120 & $1-8 \mathrm{M} / \mathrm{ft}$ & -5 to 25 & $0.1-0.3$ & \\
\hline Take-off & $50 \%$ & Deployed & - & -- & -- & - & Air & 120 & $4-8 \mathrm{M} / \mathrm{ft}$ & -5 to 25 & $0.1-0.3$ & \\
\hline Cruise & $0 \%$ & Stowed & - & GEnX & Under Wing Outboard & Small, Medium, Large & Air & 120 & $8 \mathrm{M} / \mathrm{ft}$ & $\begin{array}{r}-2 \text { to } 10(M<0.7) \\
-2 \text { to } 6.5(M>=0.7)\end{array}$ & $0.3-0.9$ & \\
\hline Cruise & $0 \%$ & Stowed & - & Ultra Fan & Under Wing Outboard & Small, Medium, Large & Air & 120 & $8 \mathrm{M} / \mathrm{ft}$ & $\begin{aligned}-2 \text { to } 10(M & <0.7) \\
-2 \text { to } 6.5(M>0 & =0.7)\end{aligned}$ & $0.3-0.9$ & \\
\hline Cruise & $0 \%$ & Stowed & - & Ultra Fan & Under Wing Outboard & Medium & Cryo & -150 & $80 \%$-flight & -2 to 5 & $0.6-0.84$ & \\
\hline Cruise & $0 \%$ & Stowed & - & Ultra Fan & Over Wing Inboard & Medium & Cryo & -150 & $80 \%$-flight & -2 to 5 & $0.6-0.84$ & \\
\hline Cruise & $0 \%$ & Stowed & - & -- & -- & - & Cryo & -150 & $80 \%$-flight & -2 to 5 & $0.6-0.84$ & \\
\hline Cruise & $0 \%$ & Stowed & - & GEnX & Under Wing Outboard & Large & Cryo & -50 & $50 \%$-flight & -2 to 5 & $0.6-0.84$ & \\
\hline Cruise & $0 \%$ & Stowed & - & GEnX & Over Wing Inboard & Large & Cryo & -50 & $50 \%$-flight & -2 to 5 & $0.6-0.84$ & \\
\hline Cruise & $0 \%$ & Stowed & - & - & - & - & Cryo & -50 & $50 \%$-flight & $\begin{array}{l}-2 \text { to } 10(M<0.7) \\
-2 \text { to } 5(M>=0.7)\end{array}$ & $0.2-0.84$ & \\
\hline Cruise & $0 \%$ & Stowed & - & -- & -- & - & Air & 120 & $8 \mathrm{M} / \mathrm{ft}$ & $\begin{array}{r}-2 \text { to } 10(M<0.7) \\
-2 \text { to } 6.5(M>=0.7)\end{array}$ & $0.3-0.9$ & Repeat Series \\
\hline Cruise & $0 \%$ & Stowed & - & - & -- & - & Air & 120 & $4-8 \mathrm{M} / \mathrm{ft}$ & $\begin{aligned}-2 \text { to } 10(M & <0.7) \\
-2 \text { to } 6.5(M & >0.7)\end{aligned}$ & $0.2-0.7$ & $\begin{array}{c}\text { Lower Re and } \\
\text { Constant q }\end{array}$ \\
\hline Cruise & $0 \%$ & Stowed & - & - & - & - & Air & 120 & $4-8 \mathrm{M} / \mathrm{ft}$ & $\begin{array}{r}-2 \text { to } 10(M<0.7) \\
-2 \text { to } 6.5(M>=0.7)\end{array}$ & $0.2-0.84$ & $\begin{array}{c}\text { Tape Over } \\
\text { Labyrinth Seal }\end{array}$ \\
\hline Cruise & $0 \%$ & Stowed & - & GEnX & Over Wing Outboard & Medium & Air & 120 & $8 \mathrm{M} / \mathrm{ft}$ & $\begin{aligned} &-2 \text { to } 10(M<0.7) \\
&-2 \text { to } 6.5(M>=0.7)\end{aligned}$ & $0.3-0.9$ & \\
\hline Cruise & $0 \%$ & Stowed & - & Ultra Fan & Over Wing Outboard & Medium & Air & 120 & $8 \mathrm{M} / \mathrm{ft}$ & $\begin{aligned}-2 \text { to } 10(M & <0.7) \\
-2 \text { to } 6.5(M & >0.7)\end{aligned}$ & $0.3-0.9$ & \\
\hline Cruise & $0 \%$ & Stowed & - & Ultra Fan & Over Wing Inboard & Medium & Air & 120 & $4-8 \mathrm{M} / \mathrm{ft}$ & 0 & $0.2-0.9$ & $\begin{array}{l}\text { Boundary Laye } \\
\text { Rakes Installed }\end{array}$ \\
\hline
\end{tabular}

\section{Results}

\section{A. Data Repeatability}

Throughout the test, planned repeat runs were performed in order to assess data repeatability. Since the focus of the test was on the cruise configuration, repeat runs were acquired at Mach numbers of 0.6, 0.80, 0.81 , and 0.82 at various Reynolds numbers in an AOA range between -2 and 5 degrees for nearly all of the various cruise configurations. These repeat runs were sometimes performed back-to-back to assess short term repeatability and sometimes they were performed at the end of a run set to assess longer term repeatability.

The methods used to analyze the data repeatability in the experiment are derived from analyses commonly used in Statistical Process Control (SPC). ${ }^{31,32}$ The Analysis of Normalized Ranges (ANOR) with mean ranges has been used frequently because of its simplicity and also because of its ability to handle varying numbers of data points within a group and varying numbers of groups within an experiment.

The process for modeling the variance of each set of repeat runs is listed below:

1. Interpolate each data set to nominal independent variable (e.g., $\alpha$ ) values $x_{i}$, if necessary;

2. For the dependent variable of interest (e.g., $C_{D}$ ), calculate the mean of the $y_{i}$ values at each $x_{i}$;

3. Calculate the residuals from the mean for each $y_{i}$ value;

4. Calculate the range of the $y_{i}$ residuals $(R=\max -\min )$ at each $x_{i}$;

5. Normalize each individual range by the quantity $d_{2}$ to produce an individual dispersion quantity $\left(R / d_{2}\right)$

The SPC quantity $d_{2}$ relates the mean range for a normal distribution to its standard deviation and is a function of the sample size as listed in Table 4. The individual dispersion quantities from each set of repeat runs are grouped together or pooled and the mean of these quantities are used to calculate an estimated standard deviation as shown in Equation 1.

$$
\hat{\sigma}=\frac{\bar{R}}{d_{2}}
$$


Table 4. Example values of range analysis quantity $d_{2}$.

\begin{tabular}{|c|c|}
\hline Number of Samples & Value of $d_{2}$ \\
\hline 2 & 1.128 \\
\hline 3 & 1.693 \\
\hline 4 & 2.059 \\
\hline 5 & 2.326 \\
\hline
\end{tabular}

An example of this process is shown in Figure 19 for $C_{D}$ at Mach 0.81 and 80\%-flight Reynolds number. The calculated standard deviation and range analysis levels are shown on the residual plot and in this particular example, the drag coefficient repeated to within \pm 0.9 counts. This process was performed for all of the repeat run sets acquired during the test.
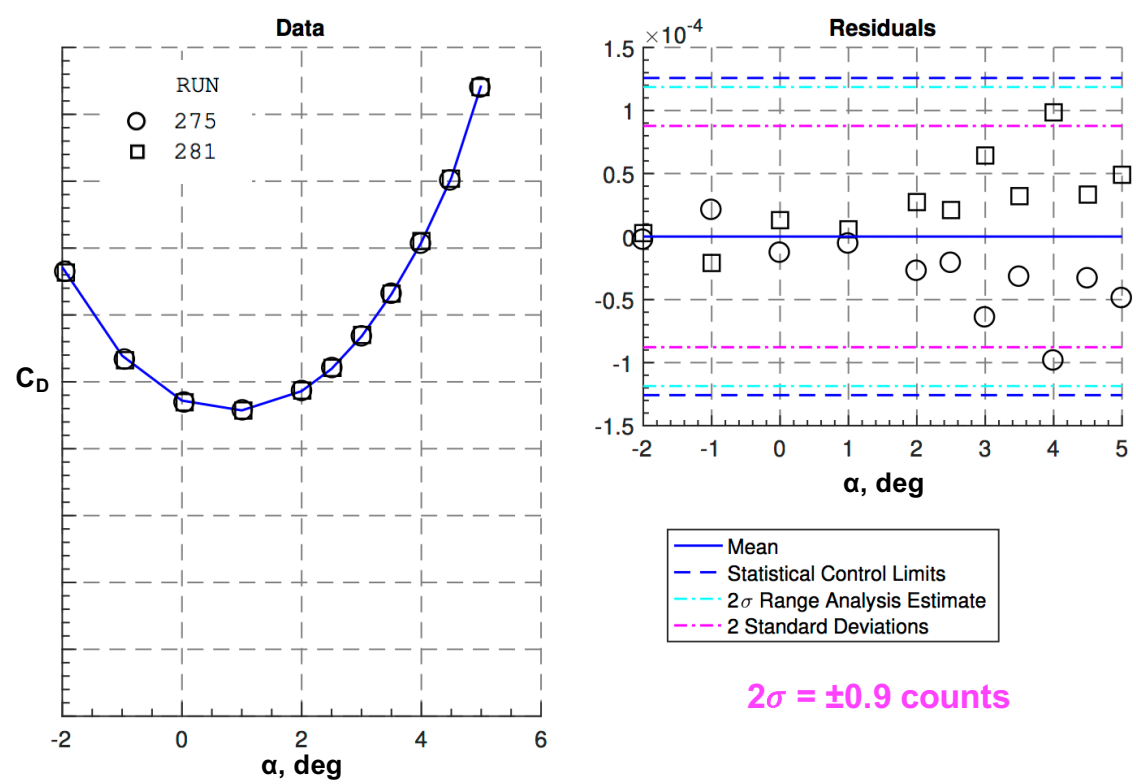

$2 \sigma= \pm 0.9$ counts

Figure 19. Example of range analysis to assess $C_{D}$ data repeatability for Mach 0.81 at $80 \%$-flight $R e$.

The individual dispersion quantities from each of the repeat run sets can be pooled together to estimate the total variation in the experiment if the variation is random. This is shown in Table 5 for several parameters of interest such as the drag coefficient and the aerodynamic efficiency parameter. As mentioned earlier, the conditional sampling data reduction technique was applied during this test and it had a noticeable effect on the data repeatability levels for some parameters such as the drag coefficient. The technique improved the repeatability of $C_{D}$ by about $25 \%$ and $M * L / D$ by about $13 \%$.

Table 5. Summary of overall data repeatability levels for the HWB cruise configuration.

\begin{tabular}{|c|c|c|}
\hline \multirow{2}{*}{ Parameter } & \multicolumn{2}{|c|}{$2 \sigma$ Data Repeatability } \\
\cline { 2 - 3 } & Averaged & Conditional Sampled \\
\hline$C_{D}$ & \pm 0.00019 & \pm 0.00014 \\
\hline$C_{L}$ & \pm 0.0011 & \pm 0.0011 \\
\hline$C_{m}$ & \pm 0.0011 & \pm 0.0010 \\
\hline$L / D$ & \pm 0.087 & \pm 0.072 \\
\hline$M * L / D$ & \pm 0.063 & \pm 0.055 \\
\hline
\end{tabular}


However, the individual dispersion quantities can also be pooled as a function of independent variables to determine whether the variation is physics-based and therefore, has a trend with an independent variable. These trends can sometimes help determine the source of data variability in the experiment. An example of this trend information is shown in Figure 20 for the repeatability of $C_{D}$ as a function of Mach number, tunnel temperature, angle-of-attack, and engine position. The repeatability levels calculated with all of the cruise configurations are shown and the levels with the baseline clean wing configuration only are also shown for reference.

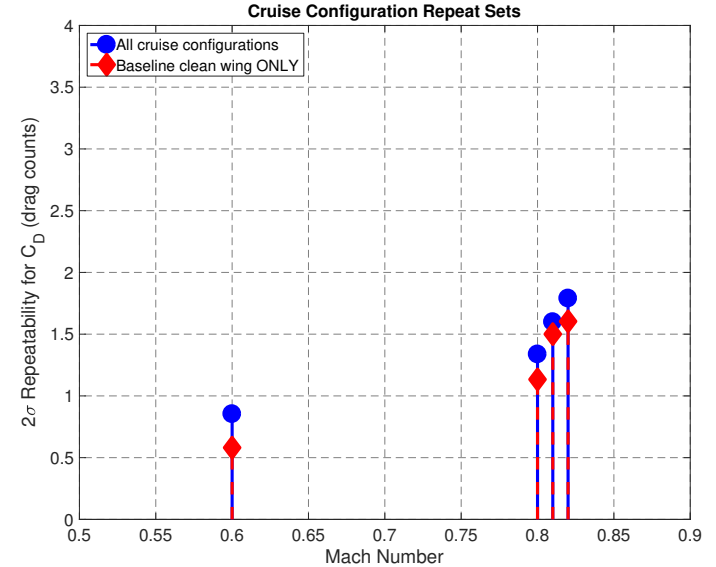

(a) Mach Number

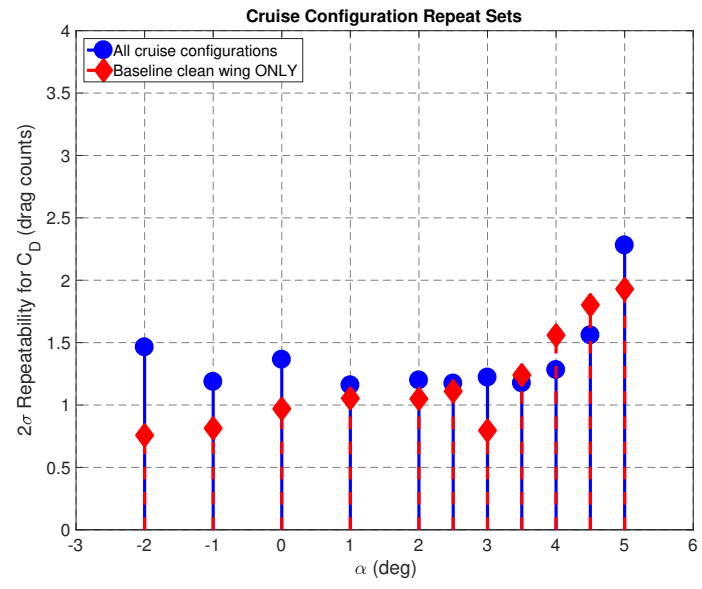

(c) Angle-of-Attack

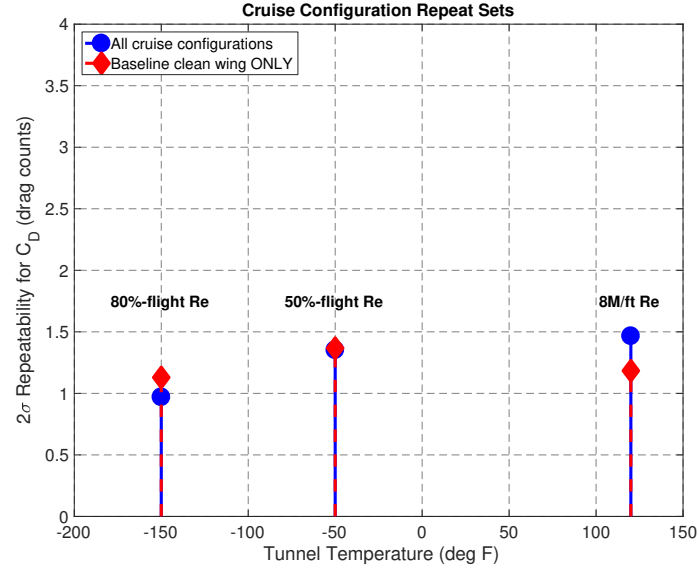

(b) Tunnel Temperature

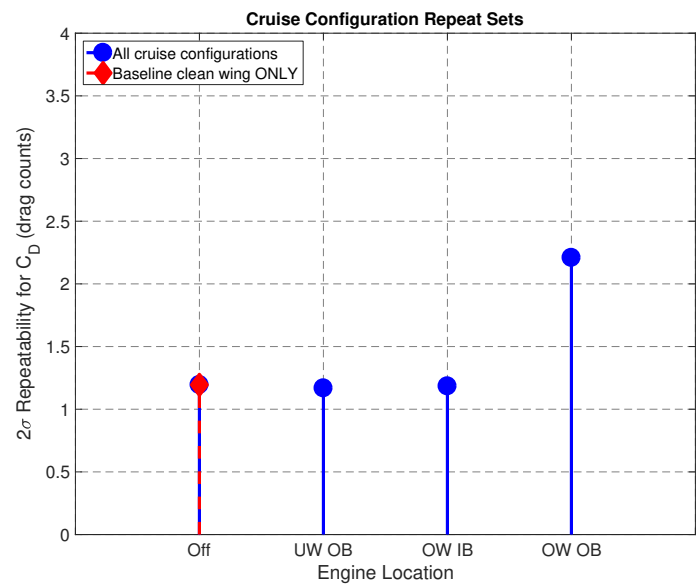

(d) Engine Position

Figure 20. Trend of $2 \sigma$ repeatability levels for $C_{D}$ with (a) Mach number, (b) tunnel temperature, (c) angle-of-attack, and (d) engine position.

It can be seen that the drag repeatability was very good overall and it was better at Mach 0.6 than at Mach $\geq 0.8$ as expected. For the clean wing configuration at Mach 0.6, the drag repeated to within \pm 0.6 counts, which is exceptional and even at Mach $\geq 0.8$, it was between \pm 1 to \pm 1.6 counts. One interesting trend that was observed was that the drag repeatability was very similar for all engine positions except for the over-wing outboard position, as shown in Figure 20(d). For that position, the drag repeatability was about two times worse than the other positions. This may perhaps be due to the fact that in the over-wing outboard position, the engine nacelle is behind the shock on the wing and has a relatively short chord running length ahead of it. Furthermore, the vortices shedding off the leading edge of the HWB forebody may also affect this position. These factors may have contributed to more unsteadiness in the data for this position as compared to the other positions and led to the elevated repeatability levels.

The overall repeatability levels from the test were very encouraging to the test team and certainly, the upgrades and lessons learned from the facility data quality improvement efforts were leveraged in the HWB test. The importance of the repeatability results is shown in Figure 21 in the comparison between 
the OWN installation and the traditional under-wing installation for both drag coefficient and aerodynamic efficiency. The pretest CFD simulations of the configuration had predicted an efficiency benefit for the OWN installation and the test results verified this prediction, in large part because the data repeatability within each configuration was excellent.

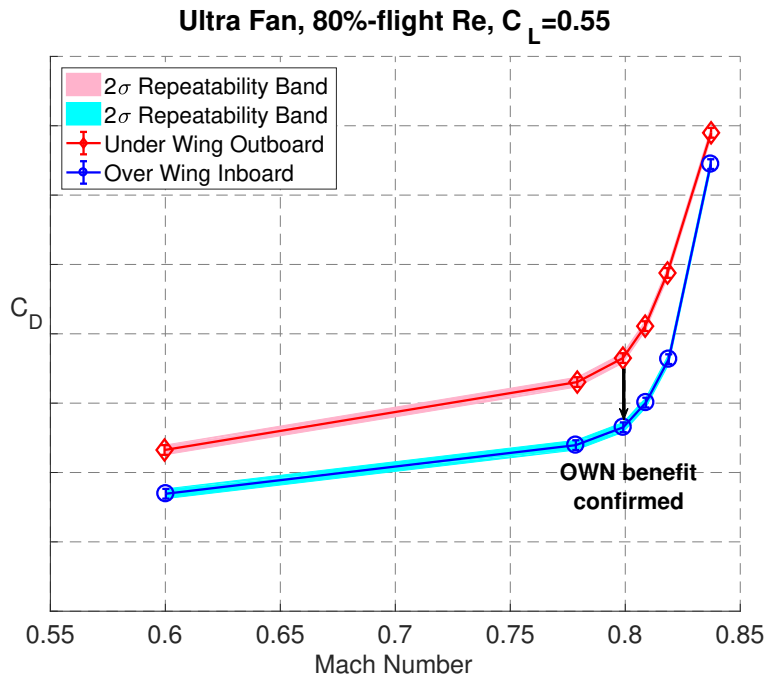

(a) Drag Coefficient

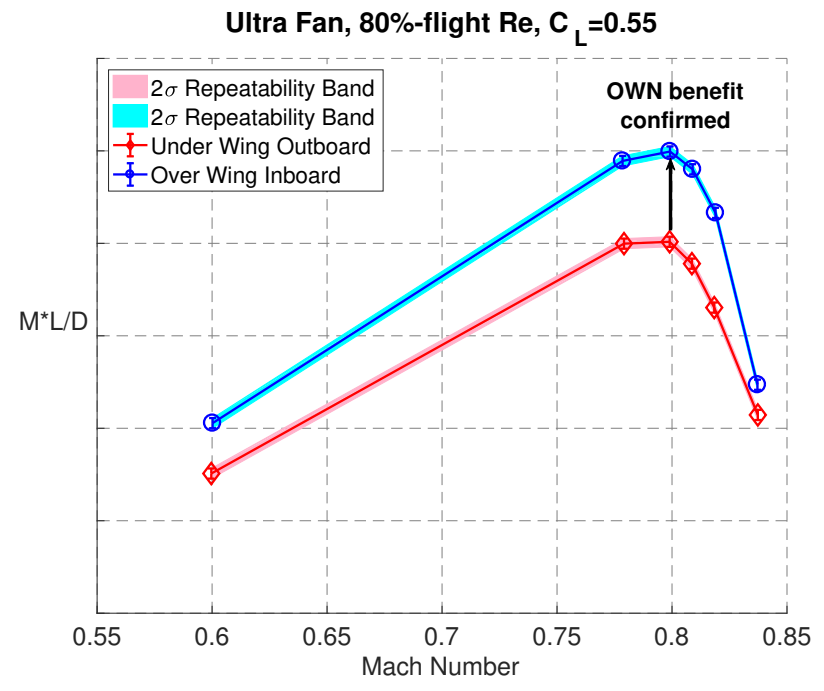

(b) Aerodynamic Efficiency

Figure 21. Comparison between over-wing nacelle installation and traditional under-wing installation for (a) drag coefficient and (b) aerodynamic efficiency for the Ultra Fan nacelle at $\mathbf{8 0 \%}$-flight $R e$ and $C_{L}=0.55$. Error bands represent the data repeatability within each configuration.

\section{B. Thermal Stability of NTF-117S Balance}

As stated earlier, the NTF-117S balance possesses RTD temperature sensors all around the balance to be able to monitor temperature gradients that may develop from the front-to-rear, top-to-bottom, and upstreamto-downstream directions. Before the improvements to the BCRS, the system could not counteract and offset the enthalpy loss at the front metric end of the balance so the temperatures in the front of the balance and balance cavity would steadily drop while the tunnel was operating at cryogenic temperatures. This produced increasing temperature gradients at the front of the balance from top-to-bottom and also increasing temperature gradients from front-to-rear, which negatively affected the balance measurements.

With the improvements to the BCRS, the thermal stability of the balance has been much better and the problems in previous transonic semispan tests were not encountered during the HWB test. Figure 22 shows the front balance temperature and balance cavity temperatures during cryogenic transonic data runs in the HWB test. The vertical lines show the range of temperatures for each measurement for all of the cruise configuration data at $-50^{\circ} \mathrm{F}$ and $-150^{\circ} \mathrm{F}$ across the Mach number and angle-of-attack ranges. The front balance and balance cavity temperatures fell within a $\pm 10^{\circ} \mathrm{F}$ range around $100^{\circ} \mathrm{F}$ even at a tunnel temperature of $-150^{\circ} \mathrm{F}$. Furthermore, the temperature gradient from top-to-bottom at the front of the balance nearly stayed within $\pm 1^{\circ} \mathrm{F}$. For comparison, in previous iterations of the BCRS, the bottom cavity temperature could drop to $40^{\circ} \mathrm{F}$ and the top-to-bottom gradient could reach more than $5^{\circ} \mathrm{F}$ when the tunnel was operating at $-50^{\circ} \mathrm{F} .{ }^{23}$ These results show that the improved BCRS can counteract the loss of enthalpy at the front of the balance very well even with the tunnel operating at $-150^{\circ} \mathrm{F}$. 


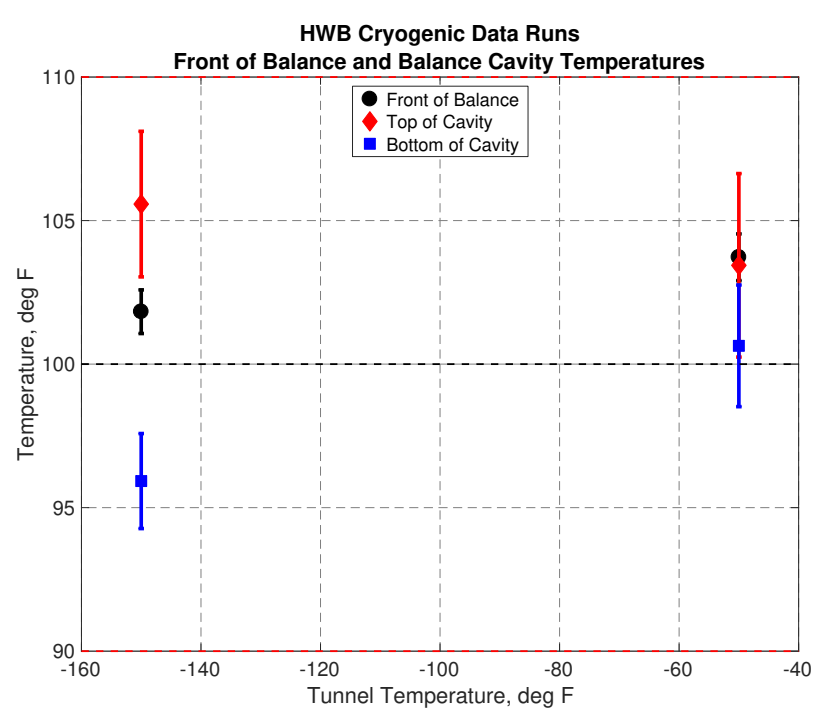

(a) Front of Balance and Balance Cavity Temperatures

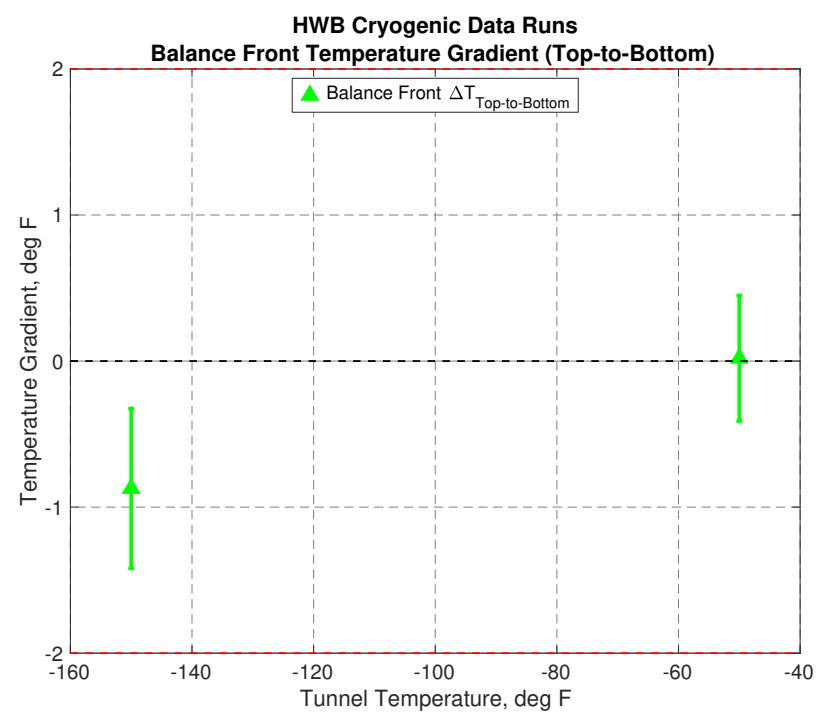

(b) Balance Front Temperature Gradient (Top-to-Bottom)

Figure 22. Thermal stability of front of balance and balance cavity.

While the improved BCRS can maintain the overall balance temperatures around $100^{\circ} \mathrm{F}$ with the tunnel operating at transonic speeds and cryogenic temperatures, small temperature gradients from the front-torear of the balance can still appear. Figure 23 shows the front-to-rear balance temperature gradients on four sides of the balance for the same cryogenic transonic data at $-50^{\circ} \mathrm{F}$ and $-150^{\circ} \mathrm{F}$. While the gradients at $-50^{\circ} \mathrm{F}$ tunnel temperature are within a $\Delta T= \pm 2^{\circ} \mathrm{F}$ band, some of the gradients at $-150^{\circ} \mathrm{F}$ tunnel temperature are outside of this band. Since it was shown that the front of the balance is performing well, the problem must be in the rear of the balance. In the same figure, temperature measurements in the rear of the SMSS and BCRS are shown and it is clear to see that at a tunnel temperature of $-150^{\circ} \mathrm{F}$, those measurements show that the rear of the SMSS and BCRS have dropped in temperature by a noticeable amount.
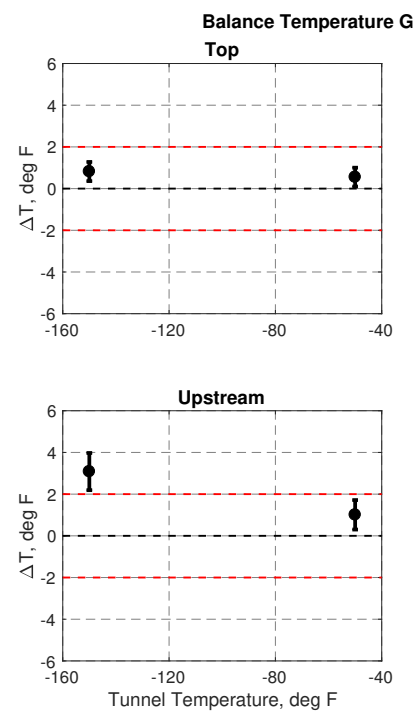

(a) Balance Temperature Gradients (Front-to-Rear)

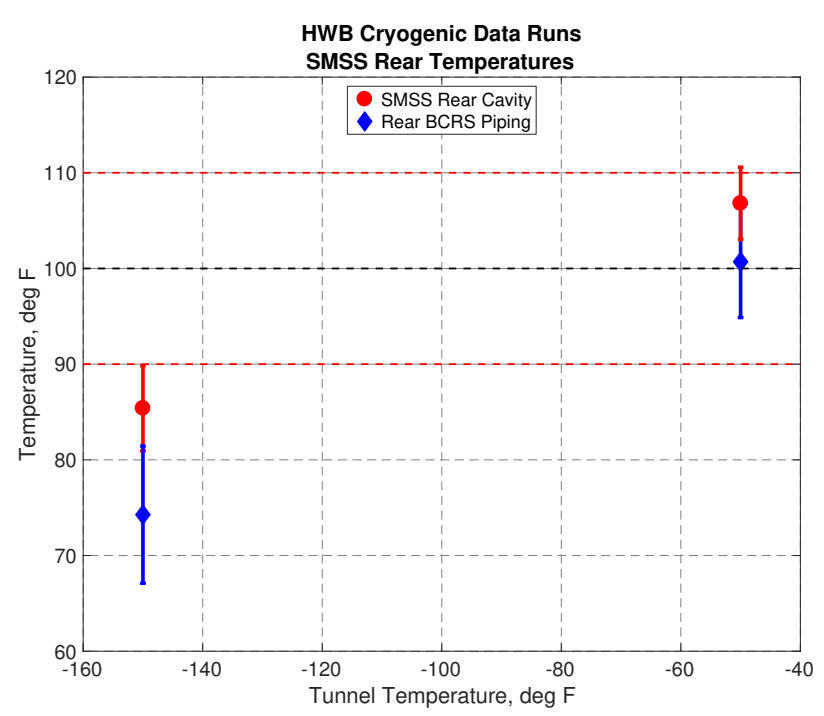

(b) SMSS Rear Temperatures

Figure 23. Thermal stability of rear of balance and rear of SMSS.

In Figure 24, the rear balance temperature and the downstream front-to-rear temperature gradient are shown as a function of time for the cryogenic data series at $-150^{\circ} \mathrm{F}$ for the HWB clean wing configuration at $80 \%$-flight Reynolds number. While the tunnel acquired data at transonic speeds, the rear balance 
temperature steadily dropped for a total of about $2^{\circ} \mathrm{F}$ in one hour and in this same time period, the downstream front-to-rear temperature gradient rose to $4^{\circ} \mathrm{F}$. These levels of temperature gradients were not significant enough to affect data quality as shown by the excellent data repeatability, however it is an area for further improvement for the BCRS. To investigate where the problem may lie, the rear balance temperature and the downstream front-to-rear temperature gradient were plotted against the BCRS rear piping temperature. This showed nearly a 1:1 correlation between the measurements suggesting that there is a small loss of enthalpy in the back of the SMSS and BCRS that is directly affecting the rear balance temperature. With this knowledge, the facility can work to improve the temperature control in the back of the SMSS and BCRS. For example, the modifications to the SMSS hardware to accommodate flow control and propulsion simulation capability have created unwanted gaps in several locations and these gaps need more attention for better sealing techniques.

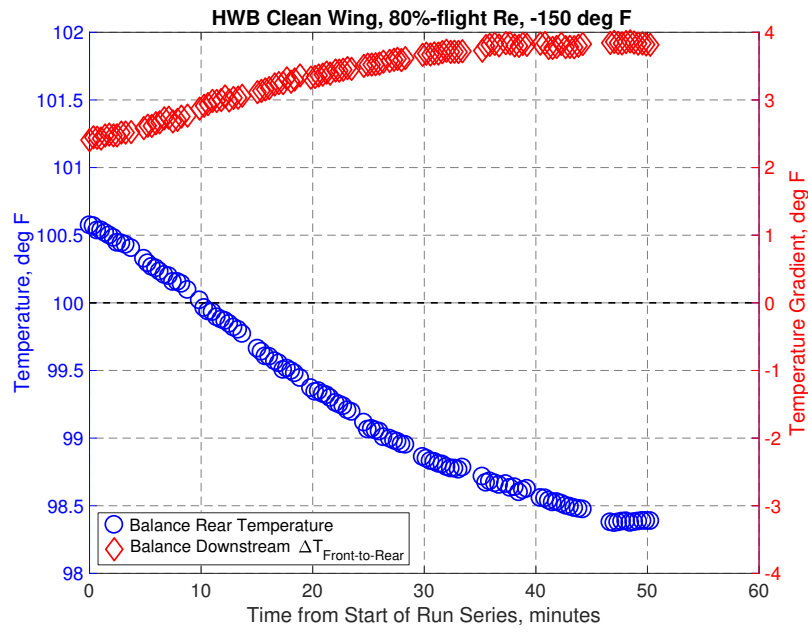

(a) Correlation with Time

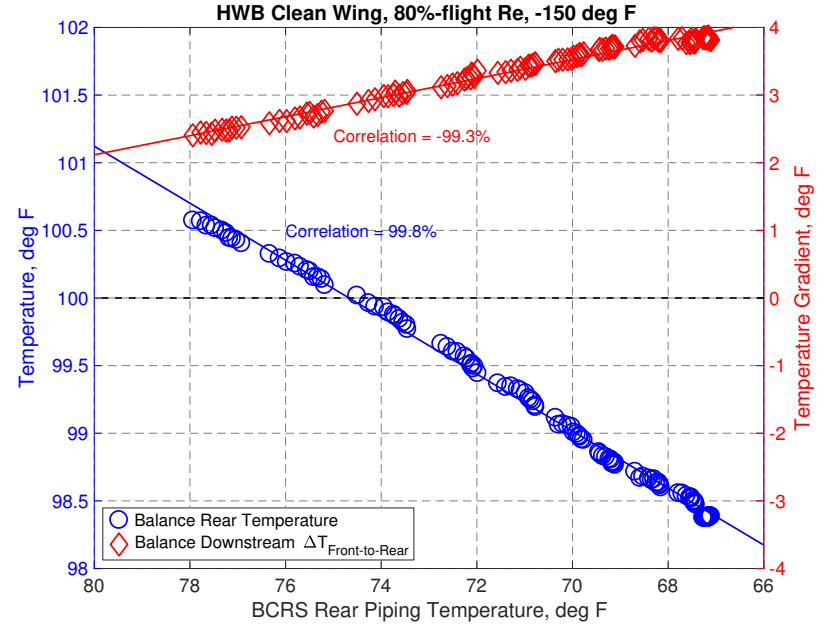

(b) Correlation with BCRS rear temperature

Figure 24. Balance rear temperature and front-to-rear temperature gradient for cryogenic data series at $-150^{\circ} \mathrm{F}$ for HWB clean wing configuration at $\mathbf{8 0 \%}$-flight $R e$.

\section{Tunnel Sidewall Boundary Layer Heights}

At the conclusion of the test, several sidewall boundary layer (BL) rakes were installed in the tunnel to measure the sidewall BL heights at various locations in the test section. The data were intended to aid LMCO in the post-test CFD-based standoff corrections as it was known that the buildup of the sidewall boundary layer was difficult to simulate in CFD and critical for determining a standoff correction. It was also known that the standoff distance of 2 inches away from the sidewall was based on historical guidelines from low-speed, high-lift tests in the NTF and that it may not be optimal for transonic testing. The measured heights would provide some information as to how the BL builds up along the NTF sidewalls and it would provide a reference for possible future standoff studies for transonic semispan testing.

Figure 25 shows the locations of the three sidewall BL rakes that were installed in the NTF test section and also shows a sketch of the BL rake. The rakes are 6 inches in height and have 28 total pressure probes of 1 inch length that are attached to the rake body and are spaced 0.125 inches apart for the first inch in height and then spaced 0.25 inches apart for the remaining 5 inches. The furthest outboard probe is longer than the other probes and also contains a static pressure orifice. Two rakes were installed at a tunnel station of 5 feet on both the nearside and farside sidewalls and the other rake was installed on the nearside sidewall at a tunnel station of 13 feet, which corresponds to the center of rotation of the SMSS turntable. The rakes at a tunnel station of 5 feet were installed on the centerline of the tunnel, while the other rake at a tunnel station of 13 feet was installed 34 inches below centerline.

The model was kept at a constant angle-of-attack of 0 degrees and the tunnel was run at Mach numbers between 0.3 and 0.9 at unit Reynolds number of $4 \mathrm{M} / \mathrm{ft}, 6 \mathrm{M} / \mathrm{ft}$, and $8 \mathrm{M} / \mathrm{ft}$. After the test, the HWB model was removed from the test section, but the BL rakes remained installed and the same tunnel conditions were repeated to provide an empty tunnel data set for comparison. The BL heights $(\delta)$ were calculated 


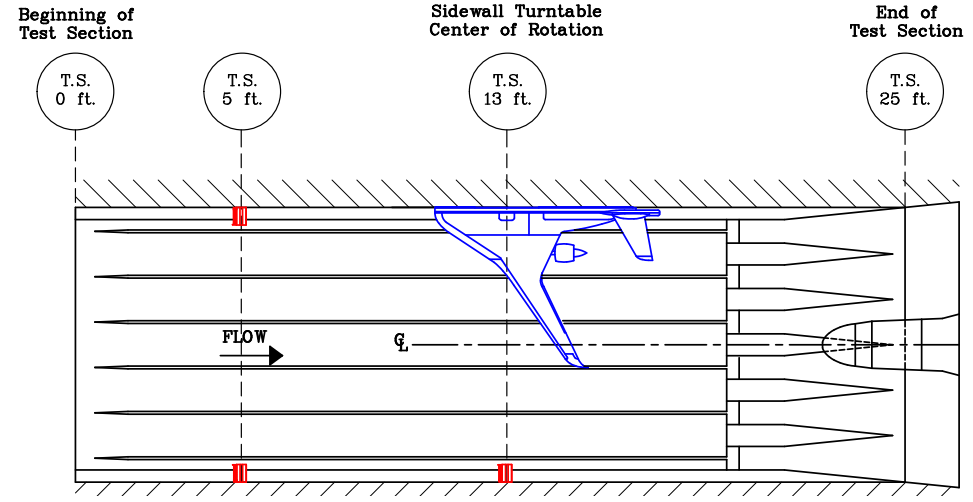

(a) Top View

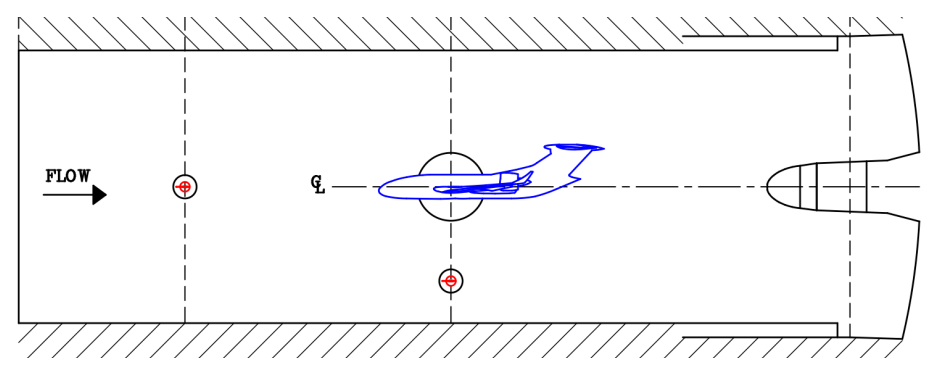

(c) Side View

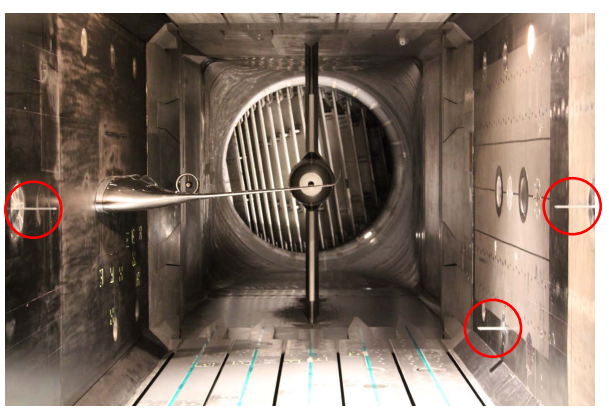

(b) Front View

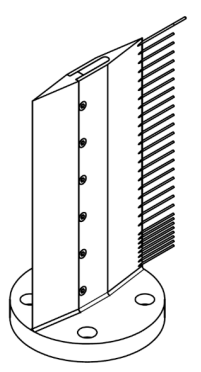

(d) NTF boundary layer rake

Figure 25. Location of sidewall boundary layer rakes in relation to HWB model in the NTF.

by examining the velocity profiles measured from the rakes and then determining the point at which the velocity was $99 \%$ of the freestream velocity as shown in Figure 26 . The displacement thicknesses $\left(\delta^{*}\right)$ were calculated by integrating to determine the area of the velocity deficit in the profiles.
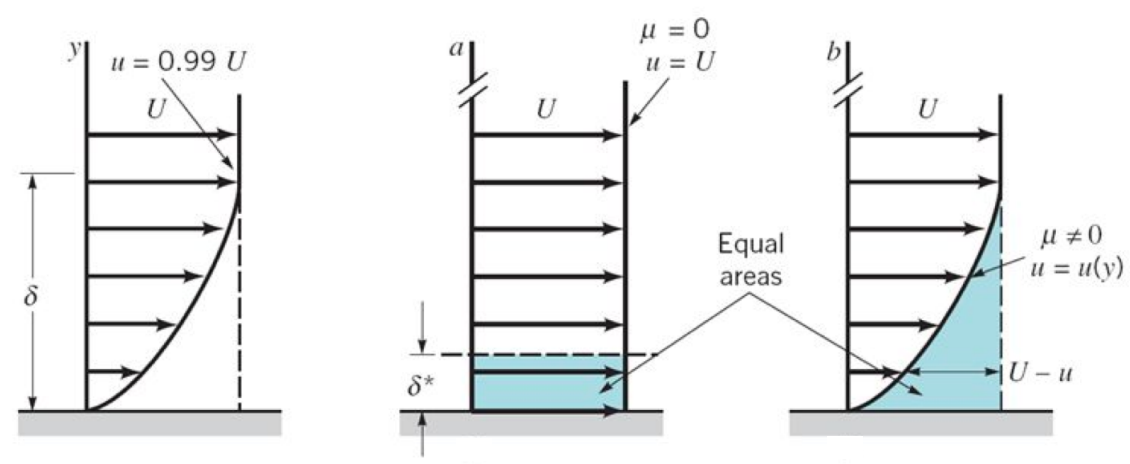

Figure 26. Boundary layer height and displacement thickness definitions.

An example of sidewall BL velocity profiles acquired at a Mach number of 0.8 and a unit Reynolds number of $8 \mathrm{M} / \mathrm{ft}$ is shown in Figure 27 for each of the rakes. The profiles behave as expected and the velocities asymptote to the freestream velocity well before the top of the BL rake. The calculated BL height and displacement thickness are also shown for reference. The BL height at tunnel station 5 feet is a little under 2 inches and the BL height at tunnel station 13 feet, where all semispan models reside, is about 3 inches. Note that the standoff distance used for the HWB model and other transonic semispan tests at NTF is 2 inches and this would place it within the sidewall boundary layer. A small portion of the model fuselage and side of body would also be within the boundary layer. This is shown in Figure 28 for the HWB model at a Mach number of 0.8 and unit Reynolds numbers of $6 \mathrm{M} / \mathrm{ft}$ and $8 \mathrm{M} / \mathrm{ft}$. 

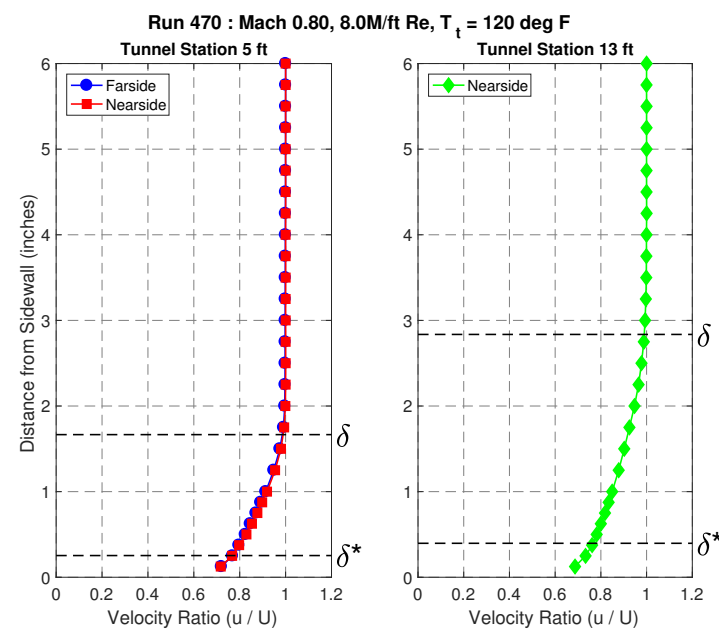

Figure 27. Sample boundary layer velocity profile at Mach 0.8 and $8 \mathrm{M} / \mathrm{ft} R e$.

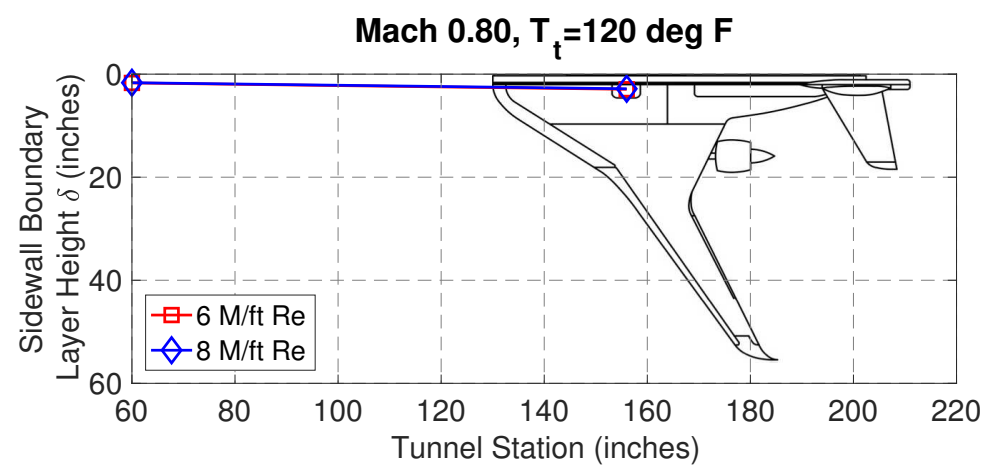

Figure 28. Sample sidewall boundary layer height at Mach 0.8 with HWB model for reference.

The BL profiles and heights did not vary due to the presence of the HWB model as shown in Figure 29. This result is not surprising due to the limited locations to install the BL rakes and because the model was kept at 0 degrees AOA. However, this was still a good result to observe. Finally, the effect of Mach number and Reynolds number on the sidewall BL heights is shown in Figure 30 for unit Reynolds numbers of $4 \mathrm{M} / \mathrm{ft}$, $6 \mathrm{M} / \mathrm{ft}$, and $8 \mathrm{M} / \mathrm{ft}$ and Mach numbers between 0.3 and 0.9 . The boundary layer heights decrease with both increasing Mach number and increasing Reynolds number as expected.

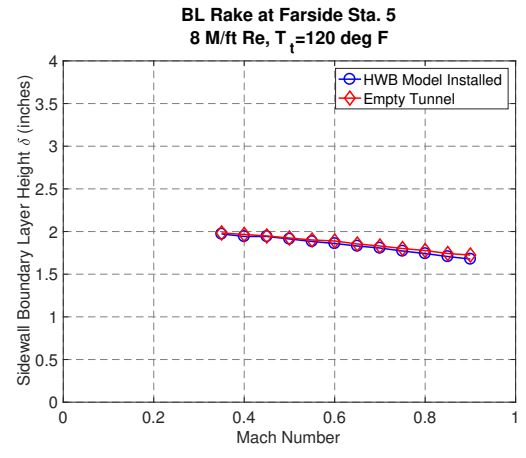

(a) Farside Sta. 5

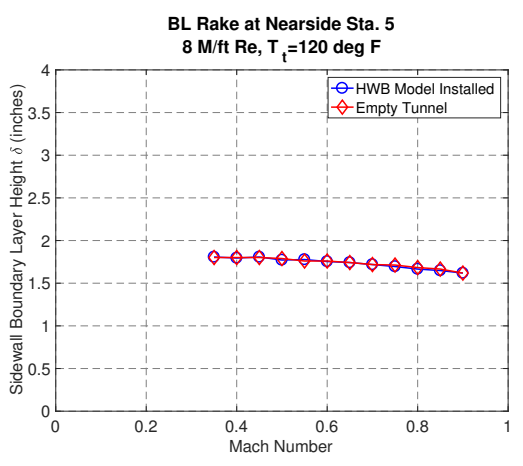

(b) Nearside Sta. 5

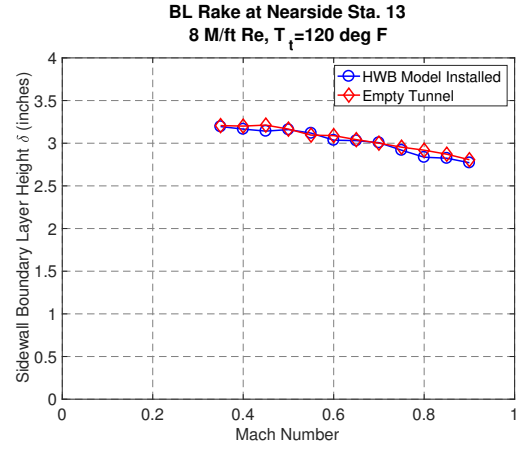

(c) Nearside Sta. 13

Figure 29. Comparison of sidewall boundary layer heights between empty tunnel and HWB model installed at a unit Reynolds number of $8 \mathrm{M} / \mathrm{ft}$. 


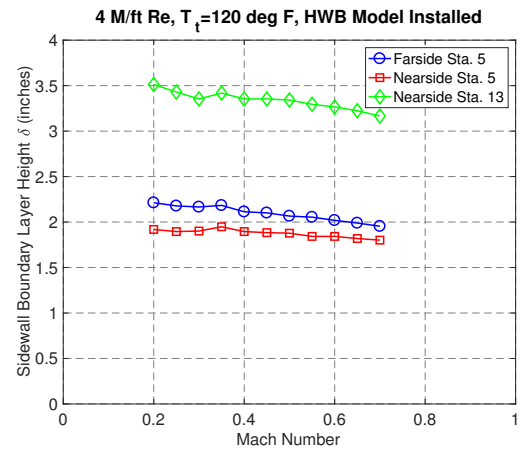

(a) $4 \mathrm{M} / \mathrm{ft} R e$

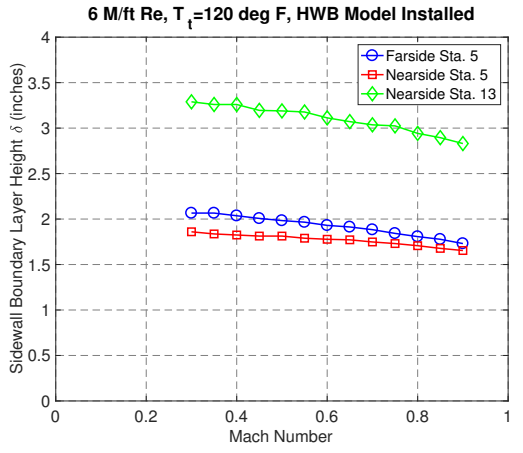

(b) $6 \mathrm{M} / \mathrm{ft} R e$

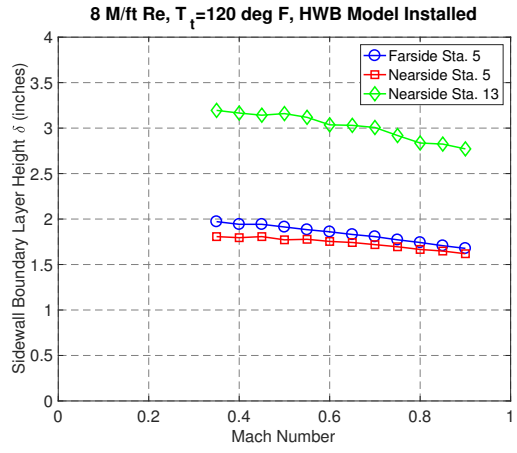

(c) $8 \mathrm{M} / \mathrm{ft} R e$

Figure 30. Effect of Mach number and Reynolds number on the sidewall boundary layer heights.

\section{Wing Twist and Deflection}

The NTF possesses a Video Model Deformation (VMD) system that uses a single camera video photogrammetry technique to track the location of individual VMD targets that are applied to the upper surface of the wing. The location of the targets in a loaded condition relative to an unloaded condition are used to calculate wing twist angles and wing deflection distances due to aerodynamic load. In the past, the system has had problems tracking targets due to glints and glares of light that are reflected off the polished shiny surfaces of NTF cryogenic models. For the HWB test, a new technique was employed using fluorescent targets and a UV light to illuminate the targets as shown in Figure 31. Two redundant Sony XCL500 CCD cameras located on the nearside sidewall were used to acquire images of the model during the test. The cameras were equipped with special Kodak No. 58 Wratten-Gelatin light filters for the green tricolor range between wavelengths of $490 \mathrm{~nm}$ and $570 \mathrm{~nm}$ that allowed them to only capture the reflection of the fluorescent targets.

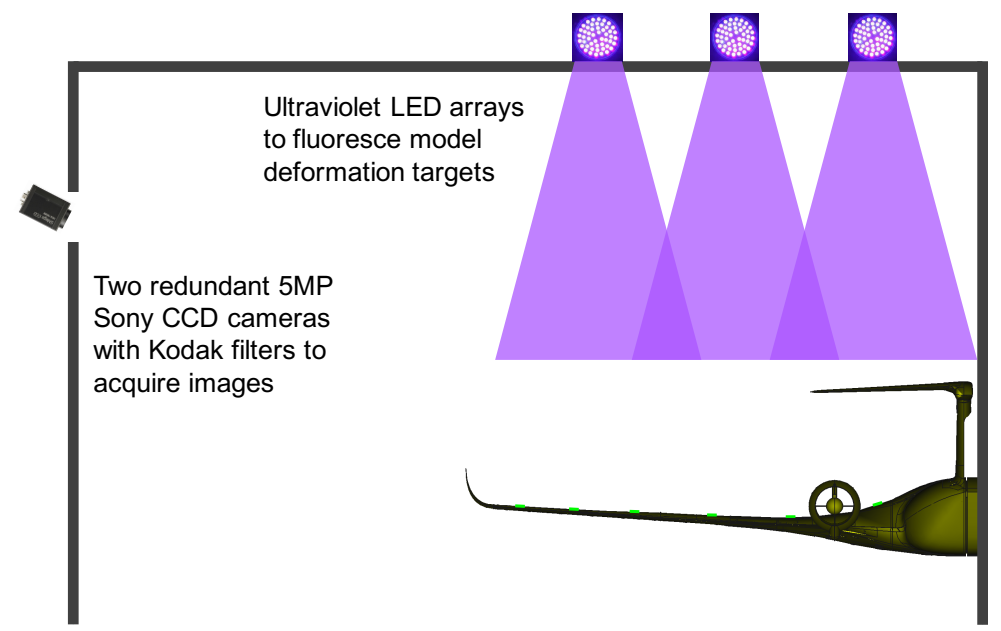

Figure 31. Setup of model deformation measurement technique at the NTF.

Figure 32 shows a closeup photo of a couple of the model deformation targets on the HWB model and also the layout of the targets on the upper surface of the wing. Six rows of targets were applied at semispan locations of $17 \%, 35 \%, 54 \%, 70 \%, 79 \%$, and $89 \%$ to capture how the wing deflects and twists under aerodynamic load. There were additional targets on areas of the model where the model would not deflect and these were used as reference targets. Sample photos and images from the VMD system are shown in Figure 33. One image shows the HWB model under UV light illumination and the other is a filtered image from the CCD camera that shows the individual targets illuminated. 


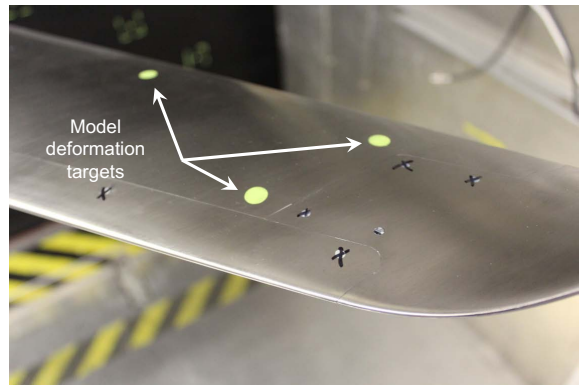

(a) Fluorescent model deformation targets

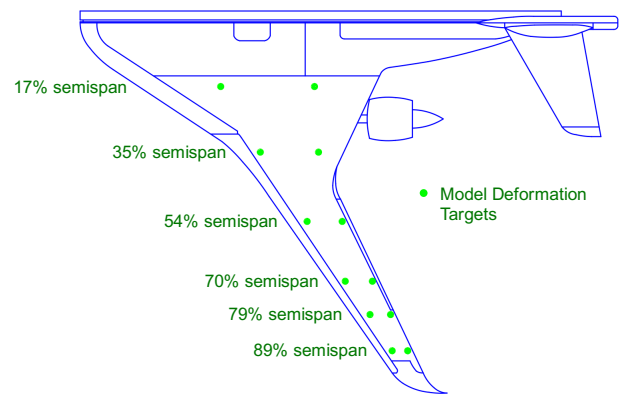

(b) Layout of targets on HWB model

Figure 32. Model deformation targets on the HWB model to measure wing twist and deflection under aerodynamic load.

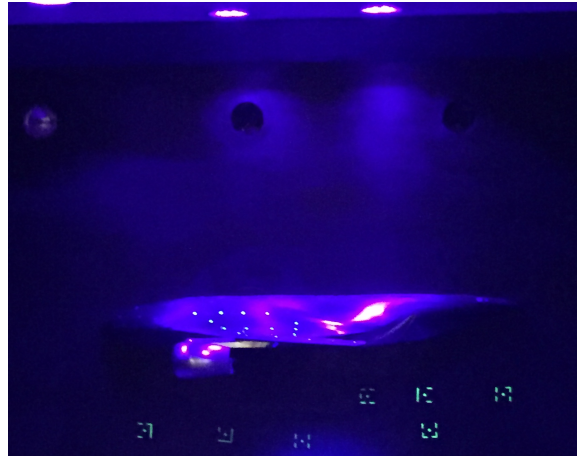

(a) UV LED arrays illuminating HWB model

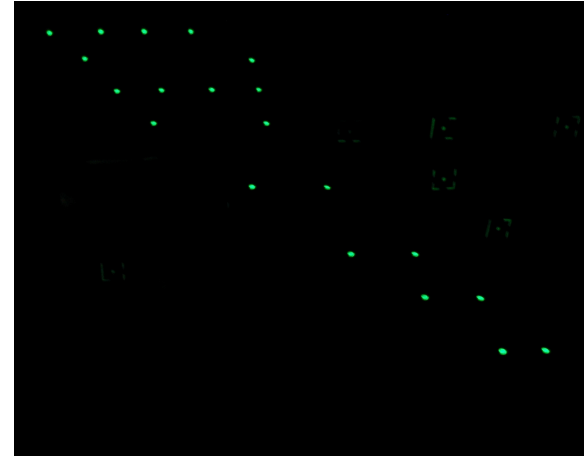

(b) Sample filtered image of model deformation targets

Figure 33. Sample images of model deformation technique for HWB model.

Finally, Figure 34 shows example results of the measured wing deflection and wing twist from the VMD system for the clean wing HWB configuration at a Mach number of 0.8 and $80 \%$-flight Reynolds number. At this highly loaded condition, the wing deflects upward a maximum of about 2 inches and twists a little over 2 degrees near the wing tip. These measurements allow for the CFD simulations to match the deflected shape of the model under load in order to get correct results.

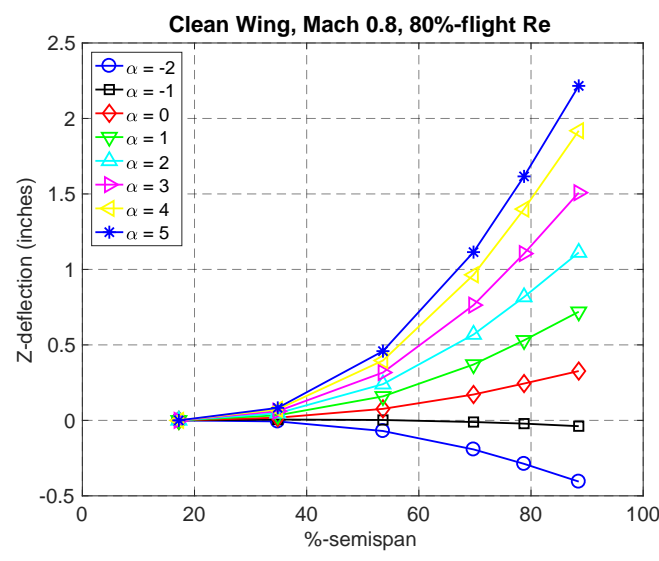

(a) Wing Z-deflection

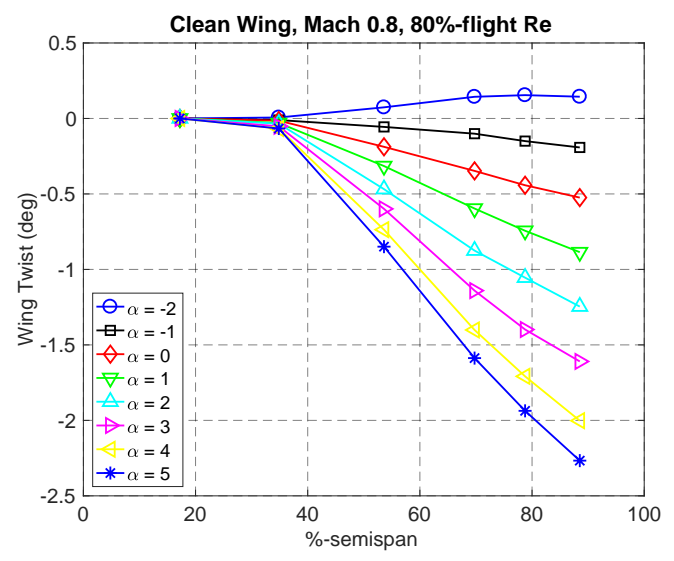

(b) Wing Twist

Figure 34. Example model deformation results for (a) Wing Deflection in Z-direction and (b) Wing Twist for the baseline clean wing configuration at Mach 0.8 and $80 \%$-flight $R e$. 


\section{E. TWICS Wall Corrections}

The 4\%-scale HWB model has a blockage of roughly $1.2 \%$ in the NTF test section and as such, the aerodynamic data need to be corrected for wall and blockage effects. The Transonic Wall Interference Correction System (TWICS) ${ }^{33-35}$ methodology at the NTF uses the measured wall pressures, model geometry, and tunnel conditions to calculate Mach, dynamic pressure, angle-of-attack, and aerodynamic coefficient corrections due to model blockage and wall interference. A number of flow singularities (line doublets generating lift; point doublets generating blockage) are used, based on model geometry and movement. The singularity strengths are first computed as a solution to the best fit of the wall signature and wall corrections are then computed by superposition. The quoted accuracy of the TWICS drag coefficient correction is \pm 1 count.

Because of the large size of the HWB model, it had significant corrections to the drag coefficient due to wall and blockage effects. The corrections were about 20 to 40 counts for Mach numbers between 0.8 and 0.9. The effect of these corrections across the Mach number range is shown in Figure 35 for the drag coefficient and aerodynamic efficiency at the cruise lift coefficient of 0.55 in the clean wing configuration. For Mach numbers at or above 0.8, the drag was reduced by about 20 counts resulting in an increase in the aerodynamic efficiency of $\Delta M * L / D=1$ at Mach 0.8. These results were typical for the other cruise configurations as well.

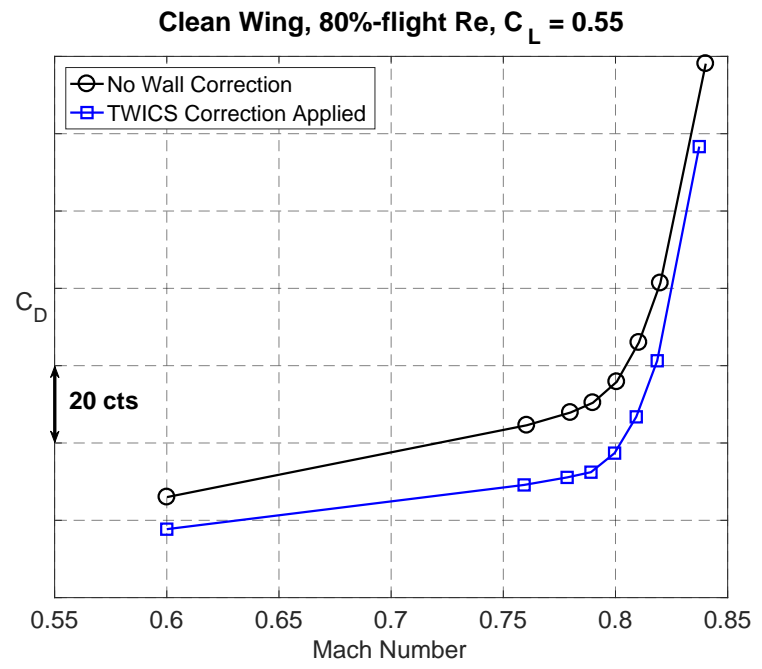

(a) Drag Coefficient

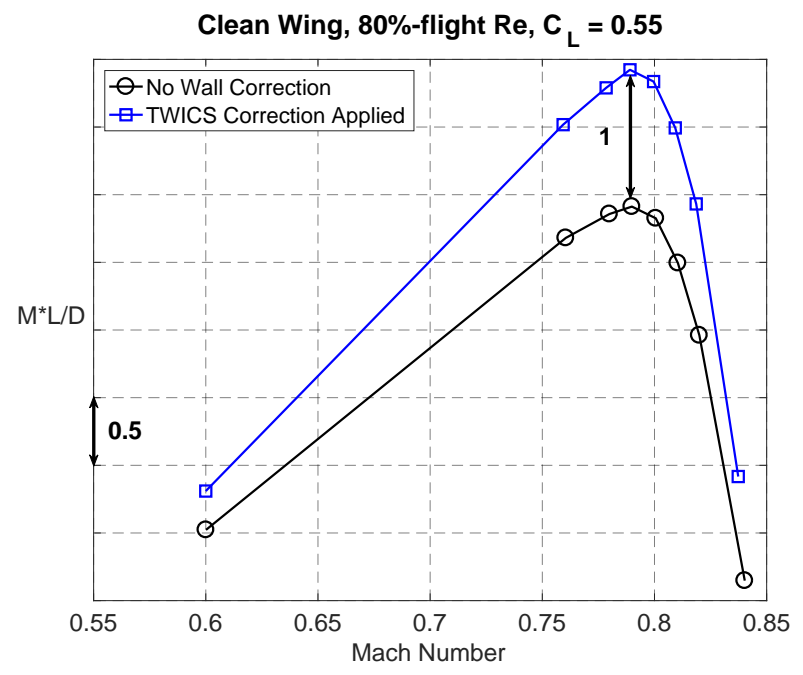

(b) Aerodynamic Efficiency

Figure 35. Sample TWICS wall correction results for (a) Drag Coefficient and (b) Aerodynamic Efficiency for the baseline clean wing configuration at $80 \%$-flight $R e$ and $C_{L}=\mathbf{0 . 5 5}$.

\section{F. Labyrinth Seal Effect}

During the test, an unexpected rise in drag was observed at $C_{L}=0$ from Mach 0.4 and continuing upward into the transonic region for the clean wing configuration at a unit Reynolds number of $8 \mathrm{M} / \mathrm{ft}$. Various theories were suggested as possible causes, but they were quickly disproved with supporting data and observations. It was known that the labyrinth seal is not a perfect seal by design and that there would be airflow into the model during wind-on tunnel operations. This was confirmed by the internal fuselage pressures that were installed for this exact purpose. However, it was assumed that the airflow into the model would be minimal due to the size of the seal gap and that it would have negligible effects on the data. However, when the labyrinth seal design was added to LMCO's CFD simulations of the HWB model, the simulations showed that there was enough airflow moving through the seal and the model to cause flow separation on the aft fuselage. To verify the simulation results, a set of runs were added to the test matrix where the labyrinth seal was taped over with aluminum tape as shown in Figure 36. There were a few small holes poked into the tape to provide pressure relief to prevent the tape from coming apart, so the tape did not provide a perfect seal, but it was a sufficient seal to help validate the simulation results.

Figure 37 shows the effect of the labyrinth seal by comparing data with the seal uncovered to data with 


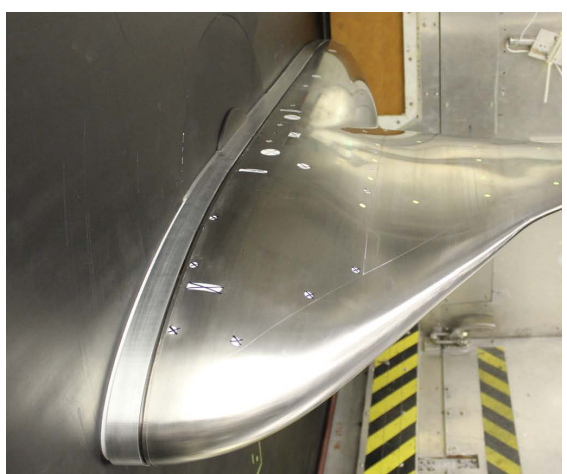

(a) Uncovered

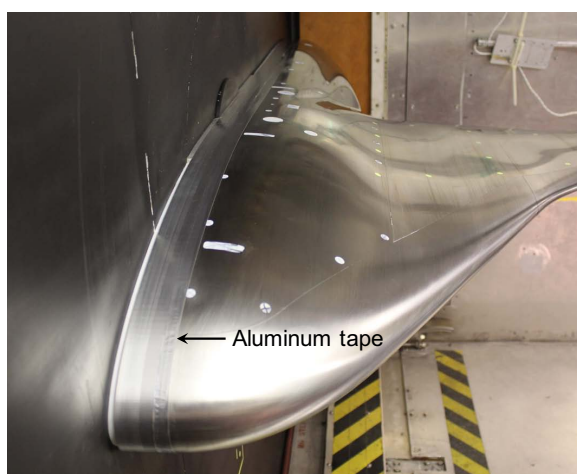

(b) Covered with aluminum tape

Figure 36. Labyrinth seal configurations.

the seal taped over. The internal fuselage pressures showed that when the seal is uncovered, air flow can quickly get into the model and it gets progressively worse with increasing Mach number in a linear fashion. As stated earlier, the aluminum tape had a few holes in it so it wasn't a perfect seal and the internal fuselage pressure data show this, however, the pressures are closer to expectations and the trend with Mach number was greatly reduced. Taping over the labyrinth seal also had a significant effect on the drag coefficient at $C_{L}=0$ as the unexpected drag rise between Mach numbers of 0.4 to 0.7 was eliminated and at Mach 0.8 , the drag was reduced by 15 counts. The CFD simulations predicted a similar shape to the curve and a similar offset at Mach 0.8, so this result provided confidence that a CFD-based standoff and labyrinth seal correction could be calculated and applied to the wind tunnel data.

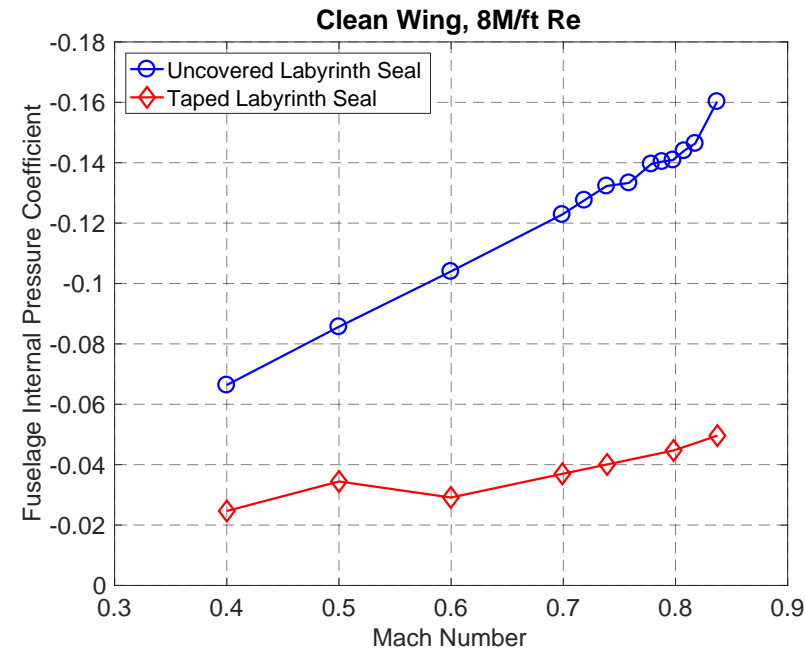

(a) Internal Fuselage Pressure

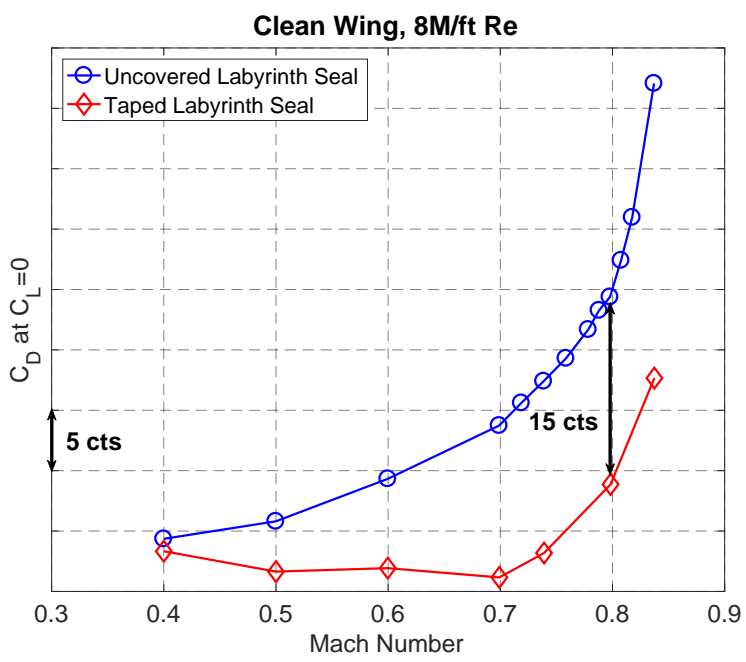

(b) Drag Coefficient at $C_{L}=0$

Figure 37. Comparison between uncovered labyrinth seal and taped labyrinth seal for (a) internal fuselage pressure and (b) $C_{D}$ at $C_{L}=0$ for the baseline clean wing configuration at $8 \mathrm{M} / \mathrm{ft} R e$.

\section{G. Nacelle Inlet Total Pressure Recovery}

The total pressure rakes in each nacelle were used to estimate the inlet recovery as a function of Mach number, Reynolds number, angle-of-attack, power setting simulated with the mass flow plugs, and especially over-wing compared to under-wing performance. Each rake total pressure was divided by the freestream total pressure to calculate a pressure ratio and an average of all of the ratios was then used to estimate the inlet total pressure recovery value for each nacelle. One of the secondary goals of the test was to show that 
the over-wing nacelle installation does not lead to increased inlet distortion as compared to the traditional under-wing installation. This would allow the operation of standard engines without the need for distortion tolerant technologies.

Figure 38 shows a comparison of the inlet total pressure recovery between Ultra Fan and GEnX engines in under-wing and over-wing positions at a Mach number of 0.8 and angle-of-attack of 0 degrees. The results for the Ultra Fan nacelle are at $80 \%$-flight Reynolds number and the results for the GEnX nacelle are at $50 \%$-flight Reynolds number. For the GEnX nacelle, the recovery values are all above $99.5 \%$ and there is not a noticeable difference between the under-wing and over-wing results. For the Ultra Fan nacelle, the recovery values are also above $99.5 \%$ for nearly all of the rake probes and there are minimal differences between the under-wing and over-wing results. However, in the over-wing installation, the bottom most probe is the only probe that shows a recovery less than $99.5 \%$.

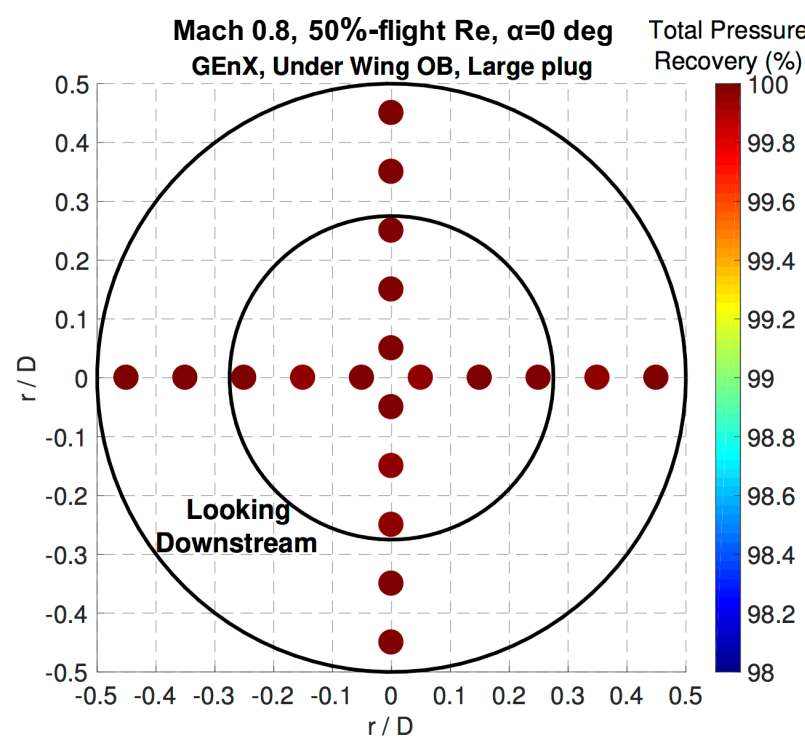

(a) GEnX, Under Wing Outboard, 50\%-flight Re

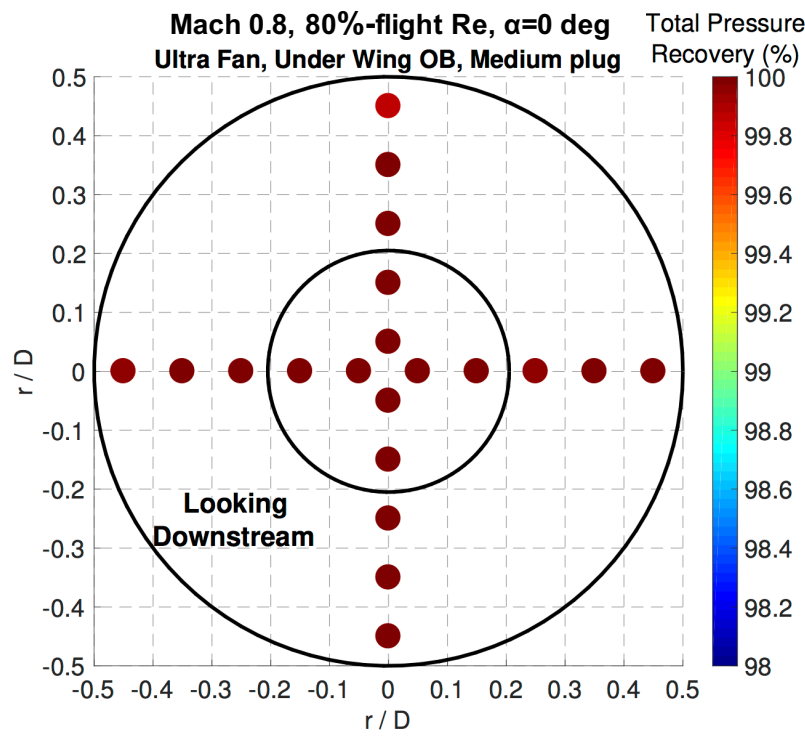

(c) Ultra Fan, Under Wing Outboard, $80 \%$-flight Re

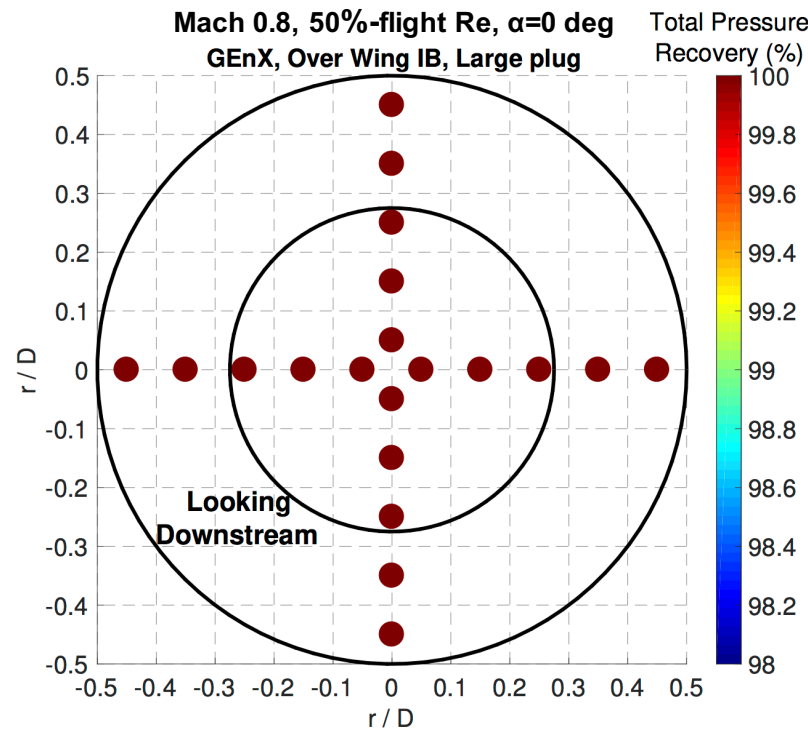

(b) GEnX, Over Wing Inboard, 50\%-flight Re

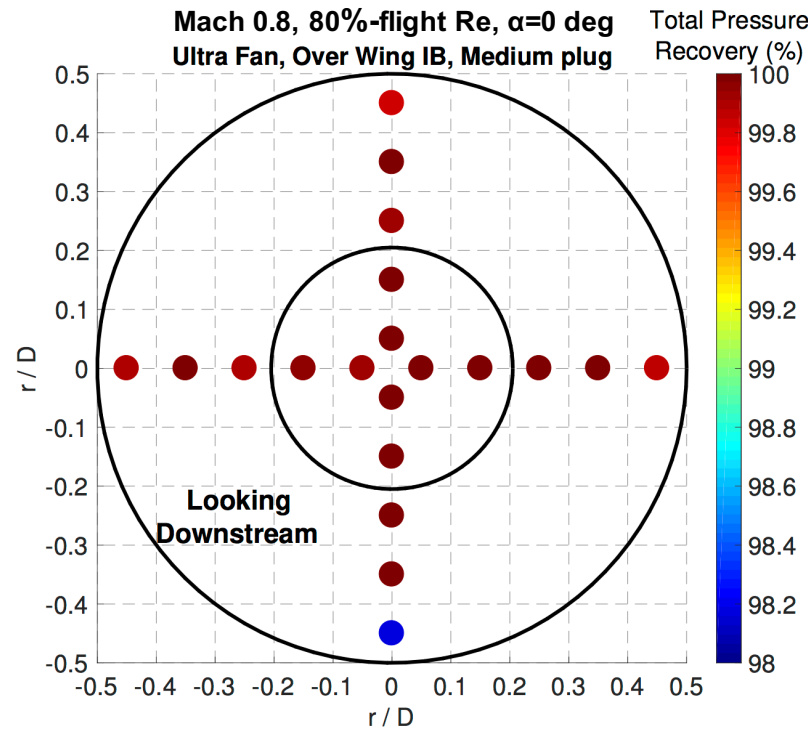

(d) Ultra Fan, Over Wing Inboard, $80 \%$-flight Re

Figure 38. Comparison of nacelle inlet total pressure recovery between Ultra Fan and GEnX engines in under-wing and over-wing positions for Mach 0.8 and $\alpha=0 \mathrm{deg}$. 
This bottom probe in the Ultra Fan nacelle in the over-wing position is most likely being affected by the junction between the pylon and nacelle inlet lip, and is possibly ingesting a small portion of the pylon boundary layer. The GEnX nacelle doesn't seem to be affected by this juncture because it has a thicker nacelle inlet lip as shown in Figure 39 and it also has a slightly less inlet scarf angle as shown earlier in Figure 11.

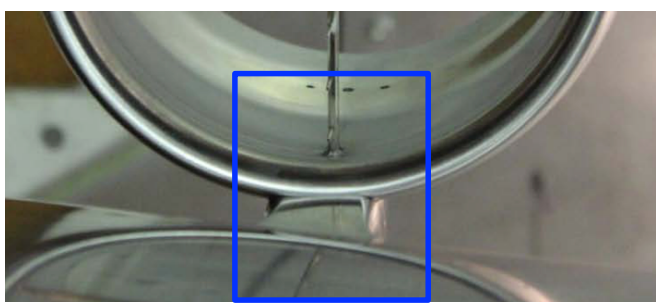

(a) Ultra Fan

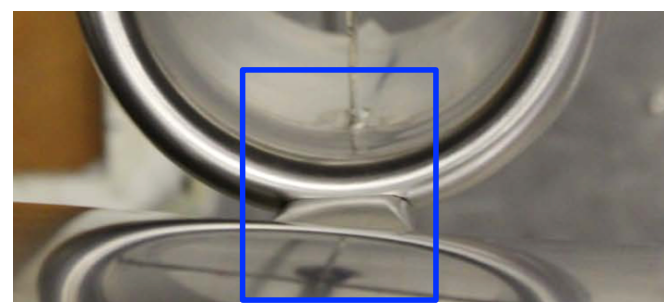

(b) GEnX

Figure 39. Photos of the juncture between the pylon and nacelle inlet lip for the (a) Ultra Fan and (b) GEnX engines.

Figure 40 shows the effect of angle-of-attack and Reynolds number on the inlet total pressure recovery for the bottom rake probe on both the GEnX and Ultra Fan nacelles in the over-wing inboard position at a Mach number of 0.8. There is very little effect of angle-of-attack or Reynolds number on the GEnX bottom probe, but the Ultra Fan bottom probe has a pronounced effect with angle-of-attack. There is also a difference with Reynolds number and since the higher Reynolds number data with the thinner boundary layer show better pressure recovery, this may again point to ingestion of a small portion of the pylon boundary layer with the Ultra Fan nacelle in the over-wing position. However, since the rest of the Ultra Fan nacelle showed excellent pressure recovery, this area near the bottom probe does not cause a huge problem and would be a relatively easy fix with a small re-design.

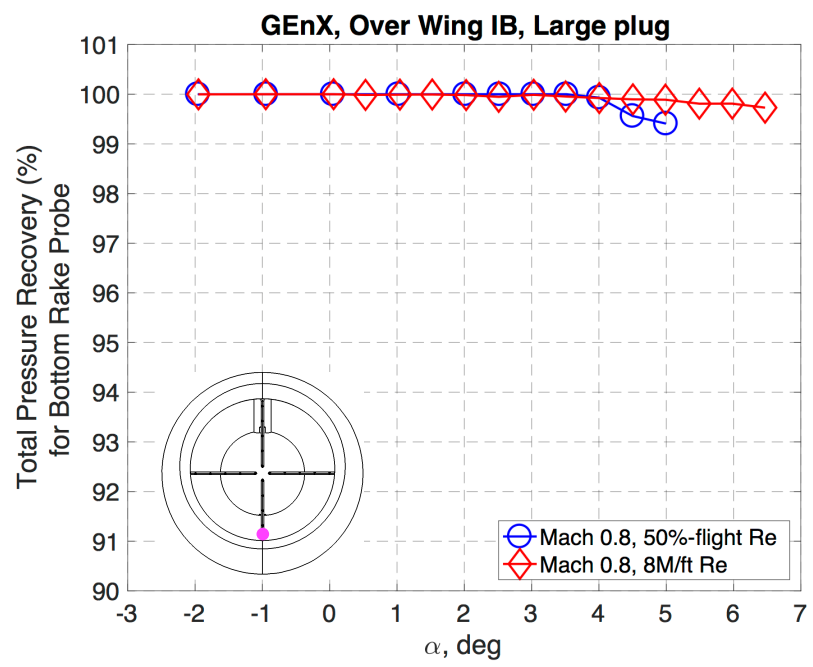

(a) GEnX

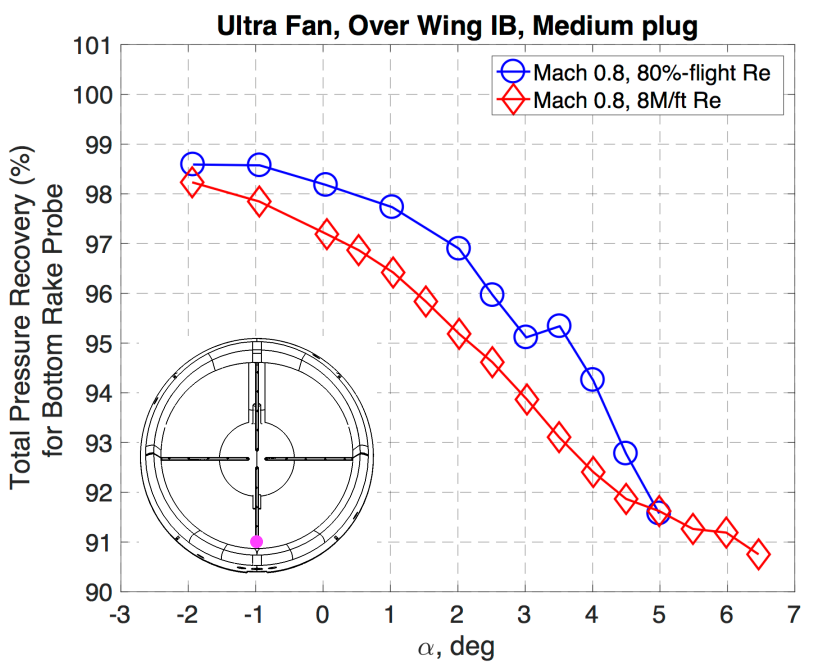

(b) Ultra Fan

Figure 40. Effect of Reynolds number and angle-of-attack on inlet total pressure recovery at Mach 0.8 for bottom rake probe on (a) GEnX and (b) Ultra Fan nacelle in over-wing inboard position. 


\section{Concluding Remarks}

A successful partnership between NASA, the Air Force Research Laboratory, and Lockheed Martin Aeronautics Company led to the success of the wind tunnel test of the Hybrid Wing Body with Over Wing Nacelles configuration in the National Transonic Facility at NASA Langley Research Center. The test validated the transonic aerodynamic performance of the HWB, validated the efficiency benefits of the OWN installation as compared to the traditional under-wing installation, and validated the performance of the conventional high-lift system. The $4 \%$-scale semispan model of the HWB could be configured in a cruise configuration or a high-lift configuration with the slat and flaps deployed. The model allowed for the GEnX and Ultra Fan flow-through engine nacelles to be installed in three different positions, one traditional under-wing position and two over-wing positions. The T-tail empennage, which was the first instance on a semispan NTF model, could be installed to assess pitch stability and control characteristics. Facility improvements such as BCRS performance and thermal stability of the force and moment balance enabled the success of the test. This led to drag repeatability measurements to within \pm 1 count which allowed for validation of HWB performance and benefits of the OWN installation. A new technique using fluorescent model deformation targets on the model improved the quality of the aeroelastic wing deflection and twist data. Additional data were acquired to aid in CFD simulations and post-test corrections to the data, which included wall interference and blockage corrections, taped labyrinth seal effects, and sidewall boundary layer heights. The successful test campaign was a key step in the technical maturation of the HWB configuration and its technologies.

\section{Acknowledgements}

The success of the HWB test at the NTF was a wonderful collaboration between individuals at NASA, AFRL, and LMCO. Everyone provided important contributions, but the authors would like to acknowledge some key contributors within NASA: Funding support were provided by the AATT Program within ARMD/AAVP and included Rich Wahls, Faye Collier, Ruben Del Rosario, Scott Anders, and Sally Viken. Technical support within NASA were provided by Eric Walker, Greg Jones, and William Milholen. Finally, the entire staff at the National Transonic Facility who worked very hard to make the test a success including Josh DeMoss, Jim O'Shaughnessy, Roy Armstrong, Bill Goad, Ronald Rauschenbach, Don Saxer, and Roman Paryz.

\section{References}

\footnotetext{
${ }^{1}$ Hooker, J. R. and Wick, A. T., "Design of the Hybrid Wing Body for Fuel Efficient Air Mobility Operations," AIAA Paper 2014-1285, AIAA, January 2014.

${ }^{2}$ Hooker, J. R., Wick, A. T., Zeune, C. H., and Agelastos, A., "Over Wing Nacelle Installations for Improved Energy Efficiency," AIAA Paper 2013-2920, AIAA, June 2013.

${ }^{3}$ Plumley, R. W. and Multhopp, D., "Energy Efficient Air Mobility: How far can we go?" AIAA Paper 2009-4314, AIAA, June 2009.

${ }^{4}$ Plumley, R. W. and Zeune, C. H., "Revolutionary Configurations: Technology Convergence Point," AIAA Paper 2017xxxx, AIAA, January 2017.

${ }^{5}$ Acosta, D. M., Guynn, M. D., Wahls, R. A., and Rosario, R. D., "Next Generation Civil Transport Aircraft Design Considerations for Improving Vehicle and System-Level Efficiency," AIAA Paper 2013-4286, AIAA, 2013. 1998.

${ }^{6}$ Campbell, R. L., "Efficient Viscous Design of Realistic Aircraft Configurations," AIAA Paper 1998-2539, AIAA, June

${ }^{7}$ Frink, N. T., Pirzadeh, S. Z., Parikh, P. C., Pandya, M. J., and Bhat, M. K., "The NASA Tetrahedral Unstructured Software System (TetrUSS)," The Aeronautical Journal, Vol. 104, No. 1040, October 2000, pp. 491-499.

${ }^{8}$ Frink, N. T., "Assessment of an Unstructured-Grid Method for Predicting 3-D Turbulent Viscous Flows," AIAA Paper 1996-0292, AIAA, January 1996.

${ }^{9}$ Pandya, M. J., Frink, N. T., Abdol-Hamid, K. S., and Chung, J. J., "Recent Enhancements to USM3D Unstructured Flow Solver for Unsteady Flows," AIAA Paper 2004-5201, AIAA, August 2004.

${ }^{10}$ Wick, A. T., Hooker, J. R., Walker, J., Chan, D. T., Plumley, R. W., and Zeune, C. H., "Hybrid Wing Body Performance Validation at the National Transonic Facility," AIAA Paper 2017-xxxx, AIAA, January 2017.

${ }^{11}$ http://www.aeronautics.nasa.gov/aavp/aetc/transonic/ntf.html, "National Transonic Facility (NTF)," .

${ }^{12}$ NTF, "NTF User Guide," NASA Document SP-2011-5-110-LaRC, NASA Langley Research Center, February 2012.

${ }^{13}$ Wahls, R. A., "The National Transonic Facility: A Research Retrospective (Invited)," AIAA Paper 2001-754, AIAA, January 2001.
} 
${ }^{14}$ Gatlin, G. M., Parker, P. A., and Owens, L. R., "Development of a Semi-Span Test Capability at the National Transonic Facility," AIAA Paper 2001-0759, AIAA, January 2001.

${ }^{15}$ Gatlin, G. M., Parker, P. A., and Owens, L. R., "Advancement of Semispan Testing at the National Transonic Facility," Journal of Aircraft, Vol. 39, No. 2, Mar-Apr 2002, pp. 339-353.

${ }^{16}$ Gatlin, G. M., Tomek, W. G., Payne, F. M., and Griffiths, R. C., "Recent Improvements in Semi-Span Testing at the National Transonic Facility (Invited)," AIAA Paper 2006-0508, AIAA, January 2006.

${ }^{17}$ Milholen-II, W. E., Jones, G. S., and Cagle, C. M., "NASA High-Reynolds Number Circulation Control Research Overview of CFD and Planned Experiments (Invited)," AIAA Paper 2010-344, AIAA, January 2010.

${ }^{18}$ Milholen-II, W. E., Jones, G. S., Chan, D. T., and Goodliff, S. L., "High-Reynolds Number Circulation Control Testing in the National Transonic Facility (Invited)," AIAA Paper 2012-0103, AIAA, January 2012.

${ }^{19}$ Milholen-II, W. E., Jones, G. S., Chan, D. T., Goodliff, S. L., Anders, S. G., Melton, L. P., Carter, M. B., Allan, B. G., and Capone, F. J., "Enhancements to the FAST-MAC Circulation Control Model and Recent High-Reynolds Number Testing in the National Transonic Facility," AIAA Paper 2013-2794, AIAA, June 2013.

${ }^{20}$ Chan, D. T., Milholen-II, W. E., Jones, G. S., and Goodliff, S. L., "Thrust Removal Methodology for the FAST-MAC Circulation Control Model Tested in the National Transonic Facility," AIAA Paper 2014-2402, AIAA, June 2014.

${ }^{21}$ Zeune, C. H., "An Overview of the Air Force's Speed Agile Concept Demonstration Program," AIAA Paper 2013-1097, AIAA, January 2013.

${ }^{22}$ Hooker, J. R., Wick, A. T., Zeune, C. H., Jones, G. S., and Milholen-II, W. E., "Design and Transonic Wind Tunnel Testing of a Cruise Efficient STOL Military Transport," AIAA Paper 2013-1100, AIAA, January 2013.

${ }^{23}$ Goodliff, S. L., Jones, G. S., Balakrishna, S., Chan, D. T., Milholen-II, W. E., Butler, D., and Cagle, C. M., "Force Measurement Improvements to the National Transonic Facility Sidewall Model Support System," AIAA Paper 2016-0648, AIAA, January 2016.

${ }^{24}$ Lynn, K. C., Toro, K. G., Chan, D. T., Balakrishna, S., and Landman, D., "Enhancements to the National Transonic Facility High-Reynolds Number Active Blowing Semi-Span Force Measurement System," Journal of Aircraft, Vol. 52, No. 6, November 2015, pp. 1736-1755.

${ }^{25}$ Paryz, R. W., "Subsonic Transonic Applied Refinements By Using Key Strategies - STARBUKS In the NASA Langley Research Center National Transonic Facility," AIAA Paper 2014-1481, AIAA, January 2014.

${ }^{26}$ Chan, D. T., Balakrishna, S., Walker, E. L., and Goodliff, S. L., "Mach Stability Improvements Using an Existing Second Throat Capability at the National Transonic Facility (Invited)," AIAA Paper 2015-0622, AIAA, January 2015.

${ }^{27}$ Milholen-II, W. E., Chokani, N., and McGhee, R. J., "Development of Semispan Model Test Techniques," Journal of Aircraft, Vol. 33, No. 6, Nov-Dec 1996, pp. 1115-1122.

${ }^{28}$ Milholen-II, W. E., "A Design Methodology for Semi-Span Model Mounting Geometries," AIAA Paper 1998-0758, AIAA, January 1998.

${ }^{29}$ Gatlin, G. M. and McGhee, R. J., "Experimental Inestigation of Semispan Model Testing Techniques," Journal of Aircraft, Vol. 34, No. 4, Jul-Aug 1997, pp. 500-505.

${ }^{30}$ Lynn, K. C., "Development of the NTF-117S Semi-Span Balance," AIAA Paper 2010-4542, AIAA, June 2010.

${ }^{31}$ Wheeler, D. and Chambers, D., Understanding Statistical Process Control, SPC Press, Knoxville, 2nd ed., 1992.

${ }^{32}$ Montgomery, D. C., Introduction to Statistical Quality Control, John Wiley and Sons, Inc., New York, 5th ed., 2005.

${ }^{33}$ Walker, E. L., "Validation of Blockage Interference Corrections in the National Transonic Facility (Invited)," AIAA Paper 2007-0750, AIAA, January 2007.

${ }^{34}$ Walker, E. L., "Statistical Calibration and Validation of a Homogeneous Ventilated Wall-Interference Correction Method for the National Transonic Facility," NASA TP 2005-213947, NASA Langley Research Center, December 2005.

${ }^{35}$ Iyer, V., Kuhl, D. D., and Walker, E. L., "Wall Interference Study of the NTF Slotted Tunnel Using Bodies of Revolution Wall Signature Data," AIAA Paper 2004-2306, AIAA, June 2004. 